\title{
GENERAL EQUILIBRIUM OLIGOPOLY AND OWNERSHIP STRUCTURE
}

\author{
JosÉ AZAR \\ School of Economics and Busines, University of Navarra and Department of Economics, IESE Business \\ School
}

XAVIER VIVES

Department of Economics, IESE Business School

\begin{abstract}
We develop a tractable general equilibrium framework in which firms are large and have market power with respect to both products and labor, and in which a firm's decisions are affected by its ownership structure. We characterize the Cournot-Walras equilibrium of an economy where each firm maximizes a share-weighted average of shareholder utilities-rendering the equilibrium independent of price normalization. In a one-sector economy, if returns to scale are non-increasing, then an increase in "effective" market concentration (which accounts for common ownership) leads to declines in employment, real wages, and the labor share. Yet when there are multiple sectors, due to an intersectoral pecuniary externality, an increase in common ownership could stimulate the economy when the elasticity of labor supply is high relative to the elasticity of substitution in product markets. We characterize for which ownership structures the monopolistically competitive limit or an oligopolistic one is attained as the number of sectors in the economy increases. When firms have heterogeneous constant returns to scale technologies, we find that an increase in common ownership leads to markets that are more concentrated.
\end{abstract}

KEYWORDS: Common ownership, portfolio diversification, macro economy, corporate governance, labor share, market power, oligopsony, antitrust policy.

\section{INTRODUCTION}

OLIGOPOLY is widespread and allegedly on the rise. Many industries are characterized by oligopolistic conditions-including, but not limited to, the digital ones dominated by GAFAM: Google (now Alphabet), Apple, Facebook, Amazon, and Microsoft. These firms, as well as others, have influence in the aggregate economy. ${ }^{1}$ Yet oligopoly is seldom

José Azar: jazar@iese.edu

Xavier Vives: xvives@iese.edu

The present paper formed the basis of the Walras-Bowley Lecture given by Xavier Vives at the 2018 North American Meeting held at University of California-Davis. This paper subsumes results in our paper entitled "Oligopoly, Macroeconomic Performance, and Competition Policy". We are grateful to two anonymous referees for useful suggestions that improved the paper's presentation. For helpful comments we thank Daron Acemoglu and Nicolas Schutz as well as participants in seminars at the ECB, UC Davis, the University of Chicago, Northwestern, NYU Stern, and Yale and in workshops at the Bank of England, CEMFI, CRESSE, HKUST, Korea University, Mannheim, and the SCE II Congress (Barcelona). Giorgia Trupia and Orestis Vravosinos provided excellent research assistance. Vives's interest in this paper's topic was spurred by early (mid-1970s) conversations with Josep Ma. Vegara and Joaquim Silvestre. We gratefully acknowledge financial support for Azar by Secretaria d'Universitats I Recerca, Generalitat de Catalunya (Ref. 2016 BP00358), for Vives by the European Research Council (Advanced Grant 789013), and for both by the Ministry of Science, Innovation and Universities with project PGC2018-096325-B-I00 (MCIU/AEI/FEDER, UE). A replication file is posted (Azar and Vives (2021)).

${ }^{1}$ In 2019, GAFAM accounted for nearly $15 \%$ of U.S. market capitalization. An extreme example is provided by Samsung and Hyundai, which are large relative to Korea's economy (Gabaix (2011)). In the United States, General Motors and Walmart-despite never employing more than $1 \%$ of the country's workforce—often figure prominently in local labor markets.

(C) 2021 The Authors. Econometrica published by John Wiley \& Sons Ltd on behalf of The Econometric Society. Xavier Vives is the corresponding author on this paper. This is an open access article under the terms of the Creative Commons Attribution License, which permits use, distribution and reproduction in any medium, provided the original work is properly cited. 
considered by macroeconomic models, which focus on monopolistic competition because of its analytical tractability. A typical limitation of monopolistic competition models is that they have no role for market concentration to play in conditioning competition because the summary statistic for competition is the elasticity of substitution. In the field of international trade, a few papers consider oligopoly_but with a continuum of sectors and hence with negligible firms in relation to the economy (Neary (2003a, 2003b), Atkeson and Burstein (2008)). Furthermore, all these papers assume that firms maximize profits even with ownership structures which induce a departure from profit maximization.

In this paper, we build a tractable general equilibrium model of oligopoly allowing for ownership diversification, characterize its equilibrium and comparative statics properties, and then use it to analyze the effect of competition policies. Our contribution is mostly methodological, although we have applied the multisector version of our model elsewhere to explain the evolution of macroeconomic magnitudes in a calibration exercise (Azar and Vives $(2018,2019 a))$. We adopt this approach in light of (a) the increasing concentration in the U.S. economy with respect to both product and labor markets and (b) the increasing extent of common ownership due to the increase in institutional investment-especially in index funds (thus, for almost $90 \%$ of S\&P 500 firms, the largest proportion of shares is held by the "Big 3" asset managers: BlackRock, Vanguard, and State Street). These trends have raised concerns of increased market power and markups (Azar (2012), Azar, Schmalz, and Tecu (2018); De Loecker, Eeckhout, and Unger (2020)) as well as calls for antitrust action and regulation of common ownership, topics that are hotly debated (see, e.g., Elhauge (2016), Posner, Scott Morton, and Weyl (2017)).

The difficulties of incorporating oligopoly into a general equilibrium framework have hindered the modeling of market power in macroeconomics and international trade. The reason is that there is no simple objective for the firm when firms are not price takers. ${ }^{2}$ In a general equilibrium, moreover, firms with pricing power will affect not only their own respective profits but also the wealth of consumers and therefore demand (these feedback effects are sometimes referred to as "Ford effects"). Firms that are large relative to factor markets also have to take into account their impact on factor prices. Gabszewicz and Vial (1972) proposed the Cournot-Walras equilibrium concept assuming firms maximize profit in general equilibrium oligopoly, but then equilibrium depends on the choice of numéraire. ${ }^{3}$ This problem has been sidestepped by assuming that there is only one good (an outside good or numéraire that owners of the firm care about; see, e.g., Mas-Colell (1982)) or that firms are small relative to the economy-be it in monopolistic competition (Hart (1983)) or sector oligopoly (Neary (2003a)).

Furthermore, a question arises as to what is the objective of the firm when there is overlapping ownership due to owners' diversification. If a firm's shareholders have holdings in competing firms, they would benefit from high prices through their effect not only on their own profits, but also on the profits of rival firms, as well as internalizing other externalities between firms (Gordon (1990), Hansen and Lott (1996)). Rotemberg (1984)

\footnotetext{
${ }^{2}$ With price-taking firms, a firm's shareholders agree unanimously that the objective of the firm should be to maximize its own profits. This result is known as the Fisher separation theorem (DeAngelo (1981)), which Hart (1979) extended to incomplete markets. In fact, Arrow's impossibility result on preference aggregation was derived precisely when attempting to generalize the theory of the firm with multiple owners (see Arrow (1984)).

${ }^{3}$ When firms have market power, the outcome of their optimization depends on what price is taken as the numéraire since by changing the numéraire the profit function is generally not a monotone transformation of the original one (see Ginsburgh (1994)).
} 
proposed a parsimonious model in which the firm's manager maximizes a weighted average of shareholders' utilities and thus internalizes inter-firm externalities. ${ }^{4}$

We build a model of oligopoly under general equilibrium, allowing firms to be large in relation to the economy, and then examine the effect of oligopoly on macroeconomic performance. The ownership structure allows investors to diversify both intra- and interindustry. We assume that firms maximize a weighted average of shareholder utilities in Cournot-Walras equilibrium. The weights in a firm's objective function are given by the influence or "control weight" of each shareholder. This approach solves the numéraire problem because indirect utilities depend only on relative prices and not on the choice of numéraire. Firms are assumed to make strategic decisions that account for the effect of their actions on prices and wages. When making decisions about hiring, for instance, a firm realizes that increasing employment could result in upward pricing pressure on real wages - reducing not only the firm's own profits but also the profits of all other firms in its shareholders' portfolios.

We develop first a base model with one sector to present our equilibrium concept and comparative static results, and then we extend it to a multi-sector economy suitable for calibration. The multi-sector model is parsimonious and identifies the key parameters driving equilibrium: elasticity of substitution across industries, elasticity of the labor supply, together with the market concentration of each industry, and the ownership structure (i.e., extent of diversification) of investors.

Our approach may shed light on some leading questions. How do output, labor demand, prices, and wages depend on market concentration and the degree of common ownership? To what extent are markups in product markets, and markdowns in the labor market, affected by how much the firm internalizes other firms' profits? Can common ownership be pro-competitive in a general equilibrium framework? How do common ownership effects change when the number of industries increases? In the presence of ownership diversification, is the monopolistically competitive limit (as described by Dixit and Stiglitz (1977)) attained when firms become small relative to the market? - and, more generally, how is that limit affected by ownership structure? Is traditional antitrust policy a complement or rather a substitute with respect to controlling common ownership when the aim is boosting employment? ${ }^{5}$

In the base model that we develop, there is one good in addition to leisure; also, the model assumes oligopoly in the product market and oligopsony in the labor market. Firms compete by setting their labor demands à la Cournot and thus have market power. There is a continuum of risk-neutral owners, who each have a proportion of their respective shares invested in one firm and have the balance invested in the market portfolio (say, an

\footnotetext{
${ }^{4}$ The maximization of the objective function "weighted average of shareholder utilities" depends on the cardinal properties of shareholders' preferences (violating Arrow's ordinal postulate). However, it can be microfounded using a purely ordinal model— provided shareholder preferences are random from the perspective of the managers who run the firms (Azar (2012, 2017), Brito, Osório, Ribeiro, and Vasconcelos (2018)). Azar (2012) and Brito et al. (2018) showed that, in a probabilistic voting setting where two managers compete for shareholder votes by developing strategic reputations, the firm's objective will be to maximize a weighted average of shareholder utilities without any coordination of the shareholders. It is worth noting that the Big 3 together have stakes that average close to $20 \%$ of each publicly traded company in the United States (Fichtner, Heemskerk, and Garcia-Bernardo (2017)). This gives them enough voting power to be pivotal often. Moreover, Aggarwal, Dahiya, and Prabhala (2019) showed that shareholder dissent hurts directors and that director elections matter because of career concerns. In particular, these authors showed that increasing the votes withheld by only $10 \%$ leads to a $24 \%$ increase in the likelihood of director turnover.

${ }^{5}$ Azar and Vives (2019b) examined the interaction of competition policy with other government policies to foster employment.
} 
index fund). This formulation is numéraire-free and allows us to characterize the equilibrium. The extent to which firms internalize rival firms' profits depends on market concentration and investor diversification. We demonstrate the existence and uniqueness of equilibrium, and then characterize its comparative statics properties, while assuming that labor supply is upward sloping (and allowing for some economies of scale in production). The results establish that, in our model of a one-sector economy, the markdown of real wages with respect to the marginal product of labor is driven by the common ownershipmodified Herfindahl-Hirschman index (HHI) for the labor market and also by labor supply elasticity (but not by product market power, since ownership is proportional to consumption). We perform comparative statics on the equilibrium (employment and real wages) with respect to market concentration and degree of common ownership, and we develop an example featuring Cobb-Douglas firms and consumers with additively separable isoelastic preferences. We find that increased market concentration-due either to fewer firms or to more diversification (common ownership)_-depresses the economy by reducing employment, output, real wages, and the labor share (if one assumes nonincreasing returns to scale). When firms have different constant returns to scale (CRS) technologies, an increase in common ownership leads to a more concentrated market (as measured by the HHI) because more efficient firms then gain market share at the expense of weaker rivals. Furthermore, the minimal relative productivity for the least productive firm to be viable is increasing in the extent of common ownership.

We extend our base model to allow for multiple sectors, and for differentiated products across sectors, with constant elasticity of substitution (CES) aggregators. The firms supplying each industry's product are finite in number and engage in Cournot competition. We allow here for investors to diversify both in an intra-industry fund and in an economy-wide index fund. In this extension, a firm deciding whether to marginally increase its employment must consider the effect of that increase on three relative prices: (i) the increase would reduce the relative price of the firm's own products, (ii) it would boost real wages, and (iii) it would increase the relative price of products in other industries (i.e., because overall consumption would increase). This third effect, referred to as inter-sector pecuniary externality, is internalized only when there is common ownership involving the firm and firms in other industries. In this case, the markdown of real wages relative to the marginal product of labor increases with the modified HHI values for the labor market and product markets, but decreases with the pecuniary externality (weighted by the extent of competitor profit internalization due to common ownership). We find that common ownership always has an anti-competitive effect when increasing intra-industry diversification, but that it can have a pro-competitive effect when increasing economywide diversification if the elasticity of labor supply is high in relation to the elasticity of substitution among product varieties. In this case, the relative impact of profit internalization on the level of market power in product markets is higher than in the labor market. It is worth remarking that when the elasticity of labor supply is high enough, an increase in economy-wide common ownership always has a pro-competitive effect, no matter how many sectors the economy has.

We then consider the limiting case when the number of sectors tends to infinity. This formulation allows us to check for whether-and, if so, under what circumstances-the monopolistically competitive market of Dixit and Stiglitz (1977) or the oligopolistic ones of Atkeson and Burstein (2008) and Neary (2003a, 2003b) are attained, in the presence of common ownership, when firms become small relative to the market; it also enables a determination of how ownership structure affects that competitive limit. We find that with incomplete asymptotic diversification, as the number of sectors $N$ in the economy grows, 
the monopolistically competitive limit is attained if there is either one firm per sector or full intra-industry common ownership. If full diversification is attained at least as fast as $1 / \sqrt{N}$, then profit internalization is positive in the limit and the Dixit-Stiglitz limit is not attained. We obtain that the limit degree of profit internalization is increasing in market concentration and in how rapidly diversification is achieved. The limit markdown may increase or decrease with profit internalization.

Competition policy in the one-sector economy can foster employment and increase real wages by reducing market concentration (with non-increasing returns) and/or the level of diversification (common ownership), which serve as complementary tools. When there are multiple sectors, it is optimal for worker-consumers to have full diversification (common ownership) economy-wide but no extra diversification intra-industry-that is, when the elasticity of substitution in product markets is low relative to the elasticity of labor supply. In this case, competition policy should seek to alter only intra-industry ownership structure.

The rest of our paper proceeds as follows. Section 2 describes some further connections with the literature. Section 3 develops a one-sector model of general equilibrium oligopoly with labor as the only factor of production; this is where we derive comparative statics results with respect to the effects of market concentration on employment, wages, and the labor share. In Section 4, we extend the model to allow for multiple sectors with differentiated products, and we then derive results that characterize the limit economy as the number of sectors approaches infinity. We also offer some illustrative calibrations of the model. Section 5 discusses the implications for competition policies, and we conclude in Section 6 with a summary and suggestions for further research. Appendix A provides more detail about the case of increasing returns in production, and the proofs of most results are given in Appendix B.

\section{CONNECTIONS WITH THE LITERATURE}

\subsection{Theory}

Our paper is related to four strands of the literature. The first is the general equilibrium with oligopoly à la the Cournot models of Gabszewicz and Vial (1972), Novshek and Sonnenschein (1978), and Mas-Colell (1982), where the proposed Cournot-Walras equilibrium assumes that firms maximize profits. Here we assume instead that a firm's manager maximizes a weighted average of shareholder utilities and also consider an ownership structure that allows for common ownership.

The second strand encompasses the macroeconomic models with Keynesian features that have incorporated market power. A precursor of those models is the work by one of Keynes's contemporaries, Michal Kalecki, on the macroeconomic effects of market power in a two-class economy (Kalecki $(1938,1954))$. The most closely related papers are perhaps Hart (1982) and d'Aspremont, Ferreira, and Gérard-Varet (1990). ${ }^{6}$ Hart's (1982) work differs from ours in assuming that firms are small relative to the overall economy and have separate owners. Unions have the labor market power in his model and so equilibrium real wages are higher than the marginal product of labor; in our model's equilibrium, real wages are lower than that marginal product.

In d'Aspremont, Ferreira, and Gérard-Varet (1990), firms are large relative to the economy; however, it is still assumed that firms maximize profits in terms of an arbitrary

${ }^{6}$ See Silvestre (1993) for a survey of the market power foundations of macroeconomic policy. 
numéraire and that they compete in prices while taking wages as given with an inelastic labor supply. We consider instead the more realistic case of an elastic labor supply, which yields a positive equilibrium real wage even when market power reduces employment to below the competitive level. Our approach differs from theirs also in that we derive measures of market concentration, discuss competition policy in a general equilibrium, and consider effects on the labor share. ${ }^{7}$ Furthermore, instead of assuming the existence of consumer-worker-owners (as is typical in the literature), we follow Kalecki (1954) and distinguish between two groups: worker-consumers and owner-consumers. Our model has a Kaleckian flavor also in relating product market power to the labor share, since in Kalecki (1938), the labor share is determined by the economy's average Lerner index.

The third strand of this literature focuses on international trade models with oligopolistic firms. Neary (2003a) considered a continuum of industries with Cournot competition in each industry, taking the marginal utility of wealth (instead of the wage) as given. Workers supply labor inelastically and firms maximize profits. Neary (2003a) found a negative relationship between the labor share and market concentration. Our work differs in that firms are large relative to the economy, and therefore have market power in both product and labor markets, and in considering the effects of firms' ownership structure. Neary (2003a) also assumed a perfectly inelastic labor supply, so that changes in market power can affect neither employment nor output in equilibrium. In contrast, we allow for an increasing labor supply function and examine more potential effects of competition policy. Atkeson and Burstein (2008) also considered a continuum of sectors with Cournot competition in each industry. These authors assumed that goods produced in a country within a sector are better substitutes than across sectors. The aim of the paper is to reproduce stylized facts regarding international relative prices.

It is worth noting that in both Atkeson and Burstein (2008) and Neary (2003a), as well as in Dixit and Stiglitz (1977), there is a representative household that owns a market portfolio in all the firms. And yet, the firms are assumed to maximize their own profits even though no shareholder would actually want this. Thus, there is a tension between the assumed ownership structure and the profit maximization assumption. The results in Section 4.3, under our assumptions with two classes of agents, in which we consider the limit as the number of sectors $N$ tends to infinity, make this tension clear. Specifically, with full asymptotic diversification as $N$ tends to infinity, we obtain the results associated to Dixit-Stiglitz or Neary (2003a) only when there is no rivals' profit internalization in the limit, and this happens when full diversification is attained very slowly (more slowly than $1 / \sqrt{N})$.

The fourth strand relates to ownership structure and oligopoly in partial equilibrium. In our model, managers internalize the control of the firm by the different owners as in Rotemberg (1984) and O'Brien and Salop (2000), but ours is not a model of the stakeholder corporation as in Magill, Quinzii, and Rochet (2015) since managers only internalize the welfare of owners. The fact that overlapping ownership may relax competition was observed by Rubinstein and Yaari (1983) and explored by Reynolds and Snapp (1986), and Bresnahan and Salop (1986). Since overlapping ownership may internalize externalities between firms, it may have ambiguous welfare effects. Indeed, overlapping ownership may increase market power and raise margins yet simultaneously internalize technological spillovers and increase productivity (López and Vives (2019)); see He and Huang

\footnotetext{
${ }^{7}$ Gabaix (2011) also considered firms that are large in relation to the economy but with no strategic interaction among them; his aim was to demonstrate how microeconomic shocks to large firms can create meaningful aggregate fluctuations. Acemoglu, Carvalho, Ozdaglar, and Tahbaz-Salehi (2012) pursued a similar goal but assumed that firms are price takers.
} 
(2017) for compatible evidence and Geng, Hau, and Lai (2016) for how vertical common ownership links may improve the internalization of patent complementarities. Here we will show how common ownership can have pro-competitive effects in a multi-sector economy. ${ }^{8}$

\subsection{Empirics}

Our approach may speak about macro trends in the economy in relation to the effects of the evolution of institutional investment and common ownership patterns, product and labor market concentration, markups and the declining labor share, the consequences for competition and investment, and the implications for policy.

The world of dispersed ownership described by Berle and Means (1932) no longer exists in the United States. The rise in institutional stock ownership over the past 35 years has been formidable. Pension, mutual, and exchange-traded funds now own the lion's share of publicly traded U.S. firms. The asset management industry is concentrated around the three largest managers (BlackRock, Vanguard, and State Street), and there has been a shift from active to passive investors (who are more diversified). This evolution of the asset management industry has transformed the ownership structure of firms. In any industry today, large firms are likely to have common shareholders with significant shares (Azar, Schmalz, and Tecu (2018)). ${ }^{9}$

Before surveying the evidence on these macroeconomic trends, let us examine what evidence there is on how common ownership might affect the incentives of managers. Common owners in an industry may have the ability and incentive to influence management. Indeed, both voice and exit can strengthen with common ownership (Edmans, Levit, and Reilly (2019)), and not pushing for aggressiveness in management contracts is a mechanism by which common owners can relax competition (Antón, Ederer, Gine, and Schmalz (2018)). Note also that, even if a fund follows a passive strategy and even if a good part of the increase in common ownership is due to the rise of passive funds, we cannot assume that the fund is a passive owner (Appel, Gormley, and Keim (2016)). In fact, large passive funds tend to exhibit a more "disciplinarian" attitude toward management (Bolton, Li, Ravina, and Rosenthal (2019)) — and institutional common owners not only internalize governance externalities but also are more likely to vote against management (He, Huang, and Zhao (2019)). ${ }^{10}$ There are, however, countervailing agency problems: Bebchuk and Hirst (2019) pointed out that index fund managers may not have incentives to monitor management (for evidence that index funds are less likely to vote against management than are active funds, see Brav, Jiang, Li, Pinnington (2019), Heath, Macciocchi, Michaely, and Ringgenberg (2019)). Schmidt and Fahlenbrach (2017) showed that increased passive ownership impedes high-cost governance activities and increases

\footnotetext{
${ }^{8}$ See Vives (2020) for an exposition of (a) the tension between market power and efficiency as an outcome of common ownership and (b) a parallel with debates in the 1960s and 1970s over the "structure-conductperformance" paradigm in the field of industrial organization.

${ }^{9}$ Minority cross-ownership is also common and has anti-competitive effects (Dietzenbacher, Smid, and Volkerink (2000), Brito et al. (2018), Nain and Wang (2018)).

${ }^{10}$ Furthermore, portfolio managers have incentives to increase, even marginally, the value of firms in their portfolio because doing so increases management fees (Lewellen and Lewellen (2018)). Jahnke's (2019) field research, based on 50 interviews with large-asset managers, supports the view that they have considerable incentives to engage in corporate governance activities for the purpose of increasing portfolio values. This finding is consistent with the views expressed by large-asset managers themselves in their "corporate stewardship" reports (e.g., BlackRock (2019)).
} 
agency costs. ${ }^{11}$ In short, the link between increased passive diversification and relaxed competition may stem either from the internalization by managers of the common owners' interests or from increased agency costs that allow managers to slack. ${ }^{12}$

Recent empirical research has renewed interest in the issue of aggregate market power and its consequences for macroeconomic outcomes. Grullon, Larkin, and Michaely (2019) claimed that concentration has increased in more than $75 \%$ of U.S. industries over the past two decades and also that firms in industries with larger increases in product market concentration have enjoyed higher profit margins and positive abnormal stock returns-suggesting that market power is the driver of these outcomes. ${ }^{13}$ De Loecker, Eeckhout, and Unger (2020) documented, for the U.S. economy, a large increase in markups (in excess of the increased overhead) and in economic profits since 1955. These authors attributed those increases to a re-allocation of market share: from low-productivity, low-markup, high-labor share firms to high-productivity, high-markup, low-labor share firms (in line with the results reported in Autor et al. (2020) and Kehrig and Vincent (2018)). Autor et al. (2020) posited that globalization and technological change lead to concentration and to the rise of what they called "superstar" firms, which have high profits and a low labor share. As the importance of superstar firms rises (with the increase in concentration), the aggregate labor share falls. ${ }^{14}$ We find that increased common ownership generates a re-allocation of market share from low-productivity, lowmarkup, high-labor share firms to high-productivity, high-markup, low-labor share firms. There is also substantial evidence that large firms have market power not just in product markets but also in labor markets. ${ }^{15}$ Furthermore, there are claims also of increasing labor market concentration (Benmelech, Bergman, and Kim (2020)).

In addition to increases in concentration as traditionally measured, recent research has shown that: (i) increased overlapping ownership of firms by financial institutions (and by funds in particular) - what we refer to as common ownership — has led to substantial increases in effective (i.e., augmented by common ownership) concentration indices in the airline and banking industries; and (ii) this greater concentration is associated with higher prices (Azar, Schmalz, and Tecu (2018)). Gutiérrez and Philippon (2017b) suggested that the increase in index and quasi-index fund ownership has played a role in the decline of aggregate investment. ${ }^{16}$ Summers (2016) and Stiglitz (2017) linked increases in market

\footnotetext{
${ }^{11}$ Hansen and Lott (1996) observed that higher agency costs may be associated with more managerial discretion when managers internalize externalities through portfolio value maximization.

${ }^{12}$ Yet when managers hold shares in their firm, agency costs could mitigate the anti-competitive effects of common ownership (see Azar (2020)).

${ }^{13}$ Autor, Dorn, Katz, Patterson, and Van Reenen (2020) stated that, for the period 1982-2012, "according to all measures of sales concentration, industries have become more concentrated on average."

${ }^{14}$ Blonigen and Pierce (2016) attributed the U.S. increase in markups to increased merger activity. Barkai (2020) documented declining labor and capital shares in the U.S. economy over the past 30 years, an outcome that is consistent with an increase in markups. Acemoglu and Restrepo (2019), summarizing a body of work, argued that automation always reduces the labor share in industry value added and that it will tend also to reduce the economy's overall labor share. For example, Acemoglu and Restrepo (2018) reported that the labor share declines more in industries (e.g., manufacturing) that are more amenable to automation.

${ }^{15} \mathrm{~A}$ thriving literature in labor economics has established that individual firms face labor supply curves that are imperfectly elastic, which is indicative of substantial labor market power (Falch (2010); Ransom and Sims (2010); Staiger, Spetz, and Phibbs (2010); Matsudaira (2013); Azar, Marinescu, and Steinbaum (2020)).

${ }^{16}$ There is an empirical debate on the validity and robustness of these results, since the Modified HHI is endogenous (see Gramlich and Grundl (2017), Kennedy, O'Brien, Song, and Waehrer (2017), O'Brien and Waehrer (2017), Dennis, Gerardi, and Schenone (2019)). Backus, Conlon, and Sinkinson (2018) adopted a structural approach in their study of the cereal industry and found large potential (but not actual) implied effects of common ownership relative to mergers.
} 
power to the potential secular stagnation of developed economies, and Boller and Morton (2020) used an event study of inclusion in the S\&P 500 index to conclude that common ownership increases profits.

Some of the recent empirical papers develop theoretical frameworks that link changes in market power to the labor share (Eggertsson, Robbins, and Wold (2018), Barkai (2020)) and to investment and interest rates (Brun and González (2017), Gutiérrez and Philippon (2017a), Eggertsson, Robbins, and Wold (2018)). The models developed by Brun and González (2017), Gutiérrez and Philippon (2017a), Eggertsson, Robbins, and Wold (2018), and Barkai (2020) are based on a monopolistic competition framework with markups determined exogenously by the parameter reflecting the elasticity of substitution among products. In all cases, only product market power is considered and the firms are assumed to have no market power in labor or capital markets. Our theoretical framework differs from these because we explicitly model oligopoly and strategic interaction between firms in general equilibrium, which enables the study of how competition policy affects the macro economy. The concern about market power in both product and labor markets is a subject of policy debate; for example, the Council of Economic Advisers produced two reports (CEA (2016a, 2016b)) on the issue of market power. Increased common ownership has also raised antitrust concerns (Baker (2016), Elhauge (2016)) and led to some bold proposals for remedies (Posner, Scott Morton, and Weyl (2017), Scott Morton and Hovenkamp (2018)) as well as calls for caution (Rock and Rubinfeld (2017)).

There is an empirical debate about the trends in concentration and markups. Indeed, Rossi-Hansberg, Sarte, and Trachter (2018) found diverging trends for aggregate (increasing) and (decreasing) concentration. Rinz (2018) and Berger, Herkenhoff, and Mongey (2019) found also that local labor market concentration has gone down. Traina (2018) and Karabarbounis and Neiman (2019) found flat markups when accounting for indirect costs of production. Increases in concentration are modest overall in both product and labor markets and/or on too broadly defined industries to generate severe product market power problems (e.g., HHIs remain below antitrust thresholds in relevant product and geographic markets; e.g., Shapiro (2018)).

The question, then, is how to reconcile the evolution of concentration in relevant markets with evidence on the evolution of margins, increasing corporate profits, and decreased labor share. According to the monopolistic competition model, margins increase when products become less differentiated. It is, however, not plausible that large changes in product differentiation happen in short spans of time. We provide an alternative framework in which market concentration and ownership structure both have a role to play.

\section{ONE-SECTOR ECONOMY WITH LARGE FIRMS}

In this section, we first describe the model in detail. We then characterize the equilibrium and comparative statics properties with homogeneous and heterogeneous firms before offering a constant elasticity example. We conclude with a summary and by describing an extension that allows for investment.

\subsection{Model Setup}

We consider an economy with (a) a finite number of firms, each of them large relative to the economy as a whole, and (b) an infinite number (a continuum) of people, each of them infinitesimal relative to the economy as a whole. There are two types of people, workers and owners, and both types consume the good produced by firms. Workers obtain income 
to pay for their consumption by offering their time to a firm in exchange for wages. The owners do not work for the firms; an owner's income derives instead from ownership of the firm's shares, which entitles the owner to control the firm and to a share of its profits. There is a unit mass of workers and a unit mass of owners, and we use $I_{W}$ and $I_{O}$ to denote (respectively) the set of workers and the set of owners. There are a total of $J$ firms in the economy.

There are two goods: a consumer good, with price $p$; and leisure, with price $w$. Each worker has a time endowment of $T$ hours but owns no other assets. Workers have preferences over consumption and leisure-as represented by the utility function $U\left(C_{i}, L_{i}\right)$, where $C_{i}$ is worker $i$ 's level of consumption and $L_{i}$ is $i$ 's labor supply. We assume that the utility function is twice continuously differentiable and satisfies $U_{C}>0, U_{L}<0, U_{C C}<0$, $U_{L L}<0$, and $U_{C L} \leq 0 .{ }^{17}$ The last of these expressions implies that the marginal utility of consumption is decreasing in labor supply.

The owners hold all of the firms' shares. We assume that the owners are divided uniformly into $J$ groups, one per firm, with owners in group $j$ owning $1-\phi+\phi / J$ of firm $j$ and owning $\phi / J$ of the other firms; here $\phi \in[0,1]$. Thus $\phi$ can be interpreted as representing the level of portfolio diversification, or (quasi-)indexation, in the economy. ${ }^{18}$

If we use $\pi_{k}$ to denote the profits of firm $k$, then the financial wealth of owner $i$ in group $j$ is given by

$$
W_{i}=\frac{1-\phi+\phi / J}{1 / J} \pi_{j}+\sum_{k \neq j} \phi \pi_{k}
$$

Total financial wealth is equal to $\sum_{k=1}^{J} \pi_{k}$, the sum of the profits of all firms. The owners obtain utility from consumption only, and for simplicity we assume that their utility function is $U^{O}\left(C_{i}\right)=C_{i}$. A firm produces using only labor as a resource, and it has a twice continuously differentiable production function $F(L)$ with $F^{\prime}>0$ and $F(0) \geq 0$. We allow for both $F^{\prime \prime} \leq 0$ and $F^{\prime \prime}>0$. We use $L_{j}$ to denote the amount of labor employed by firm $j$. Firm $j$ 's profits are $\pi_{j}=p F\left(L_{j}\right)-w L_{j}$.

We assume that firm $j$ 's objective function is to maximize a weighted average of the (indirect) utilities of its owners, where the weights are proportional to the number of shares. In other words, we suppose that ownership confers control in proportion to the shares owned. ${ }^{19}$ In this simple case, because shareholders do not work and there is only one consumption good, their indirect utility (as a function of prices, wages, and their wealth level)

\footnotetext{
${ }^{17}$ Here $U_{x}$ is the partial derivative of $U$ with respect to variable $x$, and $U_{x y}$ is the cross-derivative of $U$ with respect to $x$ and $y$.

${ }^{18}$ Each owner in group $j$ is endowed with a fraction $(1-\phi+\phi / J) /(1 / J)$ of firm $j$ and a fraction $(\phi / J) /(1 / J)=\phi$ of each of the other firms. Since the mass of the group is $1 / J$, it follows that the combined ownership in firm $j$ of all the owners in group $j$ is equal to $1-\phi+\phi / J$ and that their combined ownership in each of the other firms is $\phi / J$. The combined ownership shares of all shareholders sum to 1 for every firm:
}

$$
\underbrace{\frac{1-\phi+\phi / J}{1 / J}}_{\text {Ownership of firm } j \text { by an owner in group } j} \times \underbrace{1 / J}_{\text {Mass of group } j}+(J-1) \times \underbrace{\frac{\phi / J}{1 / J}}_{\text {Ownership of firm } j \text { by an owner in group } k \neq j} \times \underbrace{1 / J}_{\text {Mass of group } k}=1 .
$$

\footnotetext{
${ }^{19}$ See O’Brien and Salop (2000) for other possibilities that allow for cash flow and control rights to differ.
} 
is $V^{O}\left(p, w ; W_{i}\right)=W_{i} / p$. Therefore, the objective function of the firm's manager is

$$
\begin{aligned}
& \underbrace{\left(1-\phi+\frac{\phi}{J}\right)}_{\substack{\text { Control share of group } j \\
\text { in firm } j}} \underbrace{\left(1-\phi+\frac{\phi}{J}\right) \pi_{j}+\frac{\phi}{J} \sum_{k \neq j} \pi_{k}}_{\text {Indirect utility of shareholder group } j} \\
& +\sum_{k \neq j} \underbrace{\frac{\phi}{J}}_{\substack{\text { Control share of group } k \\
\text { in firm } j}} \underbrace{\frac{\left(1-\phi+\frac{\phi}{J}\right) \pi_{k}+\frac{\phi}{J} \sum_{s \neq k} \pi_{s}}{p}}_{\text {Indirect utility of shareholder group } k} .
\end{aligned}
$$

After regrouping terms, we can write the objective function as

$$
\left[\left(1-\phi+\frac{\phi}{J}\right)^{2}+(J-1)\left(\frac{\phi}{J}\right)^{2}\right] \frac{\pi_{j}}{p}+\left[2\left(1-\phi+\frac{\phi}{J}\right) \frac{\phi}{J}+(J-2)\left(\frac{\phi}{J}\right)^{2}\right] \sum_{k \neq j} \frac{\pi_{k}}{p} .
$$

After some algebra we obtain that, for firms' managers, the objective function simplifies to maximizing (in terms of the consumption good) the sum of own profits and the profits of other firms - discounted by a coefficient $\lambda$. Formally, we have

$$
\frac{\pi_{j}}{p}+\lambda \sum_{k \neq j} \frac{\pi_{k}}{p},
$$

where

$$
\lambda=\frac{(2-\phi) \phi}{(1-\phi)^{2} J+(2-\phi) \phi} .
$$

We interpret $\lambda$ as the weight—due to common ownership—-that each firm's objective function assigns to the profits of other firms relative to its own profits. This term was called the coefficient of "effective sympathy" between firms by Edgeworth (1881) and also by Cyert and DeGroot (1973). The weight $\lambda$ increases with $\phi$, or the level of portfolio diversification in the economy, and also with market concentration $1 / J$. We remark that $\lambda=0$ if $\phi=0$ and $\lambda=1$ if $\phi=1$, so all firms behave "as one" when portfolios are fully diversified.

Next, we define our concept of equilibrium.

\subsection{Equilibrium Concept}

An imperfectly competitive equilibrium with shareholder representation consists of (a) a price function that assigns consumption good prices to the production plans of firms, (b) an allocation of consumption goods, and (c) a set of production plans for firms such that the following statements hold:

(1) The prices and allocation of consumption goods are a competitive equilibrium relative to the production plans of firms.

(2) Production plans constitute a Cournot-Nash equilibrium when the objective function of each firm is a weighted average of shareholders' indirect utilities. 
It follows then that if a price function, an allocation of consumption goods, and a set of production plans for firms is an imperfectly competitive equilibrium with shareholder representation, then also a scalar multiple of prices will be an equilibrium with the same allocation of goods and production. The reason is that (a) the indirect utility function is homogeneous of degree 0 in prices and income; and (b) if a consumption and production allocation satisfies both (1) and (2) with the original price function, then it will continue to do so when prices are scaled.

We start by defining a competitive equilibrium relative to the firms' production plansin the particular model of this section, a Walrasian equilibrium conditional on the quantities of output announced by the firms. To simplify notation, we proxy firm $j$ 's production plan by the quantity $L_{j}$ of labor demanded, implicitly setting the planned production quantity equal to $F\left(L_{j}\right)$.

DEFINITION 1-Competitive Equilibrium Relative to Production Plans: A competitive equilibrium relative to $\left(L_{1}, \ldots, L_{J}\right)$ is a price system and allocation $\left[\{w, p\} ;\left\{C_{i}, L_{i}\right\}_{i \in I_{W}}\right.$, $\left\{C_{i}\right\}_{i \in I_{O}}$ ] such that the following statements hold:

(i) For $i \in I_{W},\left(C_{i}, L_{i}\right)$ maximizes $U\left(C_{i}, L_{i}\right)$ subject to $p C_{i} \leq w L_{i}$; for $i \in I_{O}, C_{i}=$ $W_{i} / p$.

(ii) Labor supply equals labor demand by the firms: $\int_{i \in I_{W}} L_{i} d i=\sum_{j=1}^{J} L_{j}$.

(iii) Total consumption equals total production: $\int_{i \in I_{W} \cup I_{O}} C_{i} d i=\sum_{j=1}^{J} F\left(L_{j}\right)$.

A price function $\mathbb{W}(\mathbf{L})$ and $\mathbb{P}(\mathbf{L})$ assigns prices $\{w, p\}$ to each labor (production) plan vector $\mathbf{L} \equiv\left(L_{1}, \ldots, L_{J}\right)$, such that for any $\mathbf{L},\left[\mathbb{W}(\mathbf{L}), \mathbb{P}(\mathbf{L}) ;\left\{C_{i}, L_{i}\right\}_{i \in I_{W}},\left\{C_{i}\right\}_{i \in I_{O}}\right]$ is a competitive equilibrium for some allocation $\left\{\left\{C_{i}, L_{i}\right\}_{i \in I_{W}},\left\{C_{i}\right\}_{i \in I_{O}}\right\}$. A given firm makes employment and production plans conditional on the price function, which captures how the firm expects prices will react to its plans as well as its expectations regarding the employment and production plans of other firms. The economy is in equilibrium when every firm's employment and production plans coincide with the expectations of all other firms.

DEFINITION 2-Cournot-Walras Equilibrium With Shareholder Representation: A Cournot-Walras equilibrium with shareholder representation is a price function $(\mathbb{W}(\cdot)$, $\mathbb{P}(\cdot))$, an allocation $\left(\left\{C_{i}^{*}, L_{i}\right\}_{i \in I_{W}},\left\{C_{i}^{*}\right\}_{i \in I_{O}}\right)$, and a set of production plans $\mathbf{L}^{*}$ such that:

(i) $\left[\mathbb{W}\left(\mathbf{L}^{*}\right), \mathbb{P}\left(\mathbf{L}^{*}\right) ;\left\{C_{i}^{*}, L_{i}\right\}_{i \in I_{W}},\left\{C_{i}^{*}\right\}_{i \in I_{O}}\right]$ is a competitive equilibrium relative to $\mathbf{L}^{*}$; and

(ii) the production plan vector $\mathbf{L}^{*}$ is a pure-strategy Nash equilibrium of a game in which players are the $J$ firms, the strategy space of firm $j$ is $[0, T]$, and the firm's payoff function is

$$
\frac{\pi_{j}}{p}+\lambda \sum_{k \neq j} \frac{\pi_{k}}{p} .
$$

Here $p=\mathbb{P}(\mathbf{L}), w=\mathbb{W}(\mathbf{L})$, and $\pi_{j}=p F\left(L_{j}\right)-w L_{j}$ for $j=1, \ldots, J$.

Note that the objective function of firm $j$ depends only on the real wage $\omega=w / p$, which is invariant to any normalization of prices.

\subsection{Characterization of Equilibrium}

Given firms' production plans, we derive the real wage-under a competitive equilibrium-by assuming that workers maximize their utility $U\left(C_{i}, L_{i}\right)$ subject to the 
budget constraint $C_{i} \leq \omega L_{i}$. This constraint is always binding because utility increases with consumption but decreases with labor. Substituting the budget constraint into the utility function of the representative worker yields the following (equivalent) maximization problem:

$$
\max _{L_{i} \in[0, T]} U\left(\omega L_{i}, L_{i}\right)
$$

Our assumptions on the utility function guarantee that the second-order condition holds. Hence the first-order condition for an interior solution implicitly defines a labor supply function $h(\omega)$ for worker $i$ such that labor supply is given by $L_{i}=\min \{h(\omega), T\}$; this coincides with aggregate (average) labor supply, which is $\int_{i \in I} L_{i} d i$. Let $\eta$ denote the elasticity of labor supply. We assume that preferences are such that $h(\cdot)$ is increasing. ${ }^{20}$

Maintained Assumption. $h^{\prime}(\omega)>0$ for $\omega \in[0, \infty)$.

This assumption is consistent with a wide range of empirical studies showing that the elasticity of labor supply with respect to wages is positive. A meta-analysis of such studies based on different methodologies (Chetty, Guren, Manoli, and Weber (2011)) concludes that the long-run elasticity of aggregate hours worked with respect to the real wage is about 0.59 . We assume that the range of the labor supply function is $[0, T]$, which-when combined with the preceding maintained assumption-guarantees the existence of an increasing inverse labor supply function $h^{-1}$ that assigns a real wage to every possible labor supply level on $[0, T]$. In a competitive equilibrium relative to the vector of labor demands by the firms, labor demand has to equal labor supply:

$$
\sum_{j=1}^{J} L_{j}=\int_{i \in I} L_{i} d i
$$

Any competitive equilibrium relative to firms' production plans $\mathbf{L}$ must satisfy either $\omega=h^{-1}(L)$ if $L=\sum_{j=1}^{J} L_{j}<T$ or $\omega \geq h^{-1}(T)$ if $L=T{ }^{21}$ In what follows, we shall use the price function that assigns $\omega=h^{-1}(T)$ when $L=T$. Given that the relative price depends only on $L$, we can define (with only minor abuse of notation) the competitive equilibrium real-wage function $\omega(L)=h^{-1}(L)$.

\subsection{Cournot-Walras Equilibrium: Existence and Characterization}

Here we identify the conditions under which symmetric equilibria exist. We also offer a characterization that relates the markdown of wages (relative to the marginal product of labor) to the economy's level of market concentration.

\footnotetext{
${ }^{20}$ We can obtain the slope of $h$ by taking the derivative with respect to the real wage in the first-order condition. This procedure yields

$$
\operatorname{sgn}\left\{h^{\prime}\right\}=\operatorname{sgn}\left\{U_{C}+\left(U_{C C} \omega+U_{C L}\right) \int_{i \in I} L_{i} d i\right\} .
$$

${ }^{21}$ The implication here is that the competitive equilibrium real wage as a function of $\left(L_{1}, \ldots, L_{J}\right)$ depends on firms' individual labor demands only through their effect on aggregate labor demand $L$.
} 
The objective of firm $j$ 's manager is to choose an $L_{j}$ that maximizes the following expression:

$$
F\left(L_{j}\right)-\omega(L) L_{j}+\lambda \sum_{k \neq j}\left[F\left(L_{k}\right)-\omega(L) L_{k}\right] .
$$

We start by noting that firm $j$ 's best response depends only on the aggregate response of its rivals, $\sum_{k \neq j} L_{k}$, because the marginal return to firm $j$ is $F^{\prime}\left(L_{j}\right)-\omega(L)-\left(L_{j}+\right.$ $\left.\lambda \sum_{k \neq j} L_{k}\right) \omega^{\prime}(L)$. Let $E_{\omega^{\prime}} \equiv-\omega^{\prime \prime} L / \omega^{\prime}$ denote the elasticity of the inverse labor supply's slope. Then a sufficient condition for the game (among firms) to be of the "strategic substitutes" variety is that $E_{\omega^{\prime}}<1$. In this case, one firm's increase in labor demand is met by reductions in labor demand by the other firms and so there is an equilibrium (Vives (1999), Theorem 2.7). Furthermore, if $F^{\prime \prime} \leq 0$ and $E_{\omega^{\prime}}<1$, then the objective of the firm is strictly concave and the slope of its best response to a rival's change in labor demand is greater than -1 . In that event, the equilibrium is unique (per Vives (1999), Theorem 2.8).

PROPOSITION 1: Let $E_{\omega^{\prime}}<1$. Then the game among firms is one of strategic substitutes and an equilibrium exists. Moreover, if returns are non-increasing (i.e., if $\left.F^{\prime \prime} \leq 0\right)$, then the equilibrium is unique, symmetric, and locally stable under continuous adjustment (unless $F^{\prime \prime}=0$ and $\left.\lambda=1\right)$. In an interior symmetric equilibrium, if the total employment level $L^{*} \in$ $(0, T)$, then the following statements hold:

(a) The markdown of the real wage $\omega^{*}$ is given by

$$
\mu \equiv \frac{F^{\prime}\left(L^{*} / J\right)-\omega\left(L^{*}\right)}{\omega\left(L^{*}\right)}=\frac{H}{\eta\left(L^{*}\right)},
$$

where $H=(1+\lambda(J-1)) / J$ is the modified HHI of the labor market and where $H$ and $\mu$ are each increasing in $\phi$.

(b) Both $L^{*}$ and $\omega^{*}$ are increasing in $J$ and decreasing in $\phi$.

(c) The share of a firm's income received by workers, $\left(\omega\left(L^{*}\right) L^{*}\right) /\left(J F\left(L^{*} / J\right)\right)$, decreases with $\phi$.

REMARK: To ensure a unique equilibrium, it is enough that $-F^{\prime \prime}\left(L_{j}\right)+(1-\lambda) \omega^{\prime}(L)>$ 0 if the second-order condition holds. In this case, we may have a unique (and symmetric) equilibrium with moderately increasing returns. Note that $F^{\prime \prime}<0$ is required if the condition is to hold for all $\lambda$. Furthermore, it is possible to show that, together, the inequalities $-F^{\prime \prime}+(1-\lambda) \omega^{\prime}>0$ and $\omega^{\prime}>0$ are enough to ensure that a symmetric equilibrium exists and, in addition, that there are no asymmetric equilibria. And if also $F^{\prime \prime} \leq 0$ and $E_{\omega^{\prime}}<2$ when evaluated at a candidate symmetric equilibrium, then the symmetric equilibrium is unique for any $\lambda$ (and is stable provided that $\lambda<1$ ). These relaxed conditions allow for strategies that are strategic complements.

REMARK: If $F^{\prime \prime}=0$ (constant returns) and if $\lambda=1(\phi=1$, firm cartel), then there is a unique symmetric equilibrium and also multiple asymmetric equilibria, with each firm employing an arbitrary amount between zero and the monopoly level of employment and with the total employment by firms equal to that under monopoly. The reason is that the shareholders in this case are indifferent over which firm engages in the actual production.

REMARK: The market power friction at a symmetric equilibrium can also be expressed in terms of the markup of product prices over the effective marginal cost of labor (mc $\equiv$ 
$\left.w / F^{\prime}(L / J N)\right)$,

$$
\tilde{\mu} \equiv \frac{p-\mathrm{mc}}{p}=\frac{\mu}{1+\mu},
$$

rather than in terms of the markdown

$$
\mu=\frac{F^{\prime}-w / p}{w / p}=\frac{p-\mathrm{mc}}{\mathrm{mc}} .
$$

The Lerner-type misalignment of the marginal product of labor and the real wage (i.e., the markdown $\mu$ of real wages) is equal to the modified HHI divided by the elasticity $\eta$ of labor supply. The question then arises of why there is no effect of the concentration and/or the residual demand elasticity in the product market. In other words: why does there seem to be no effect of product market power? The reason is that, when there is a single good, this effect (equal to product market modified HHI divided by demand elasticity) is exactly compensated by the effect of owners internalizing their consumption-that is, since they are also consumers of the product that the oligopolistic firms produce. Owners use firm profits only for purchasing the good. ${ }^{22}$

\section{Additively Separable Isoelastic Preferences and Cobb-Douglas Production}

We now consider a special case of the model, one in which consumer-workers have separable isoelastic preferences over consumption and leisure:

$$
U\left(C_{i}, L_{i}\right)=\frac{C_{i}^{1-\sigma}}{1-\sigma}-\chi \frac{L_{i}^{1+\xi}}{1+\xi},
$$

where $\sigma \in(0,1)$ and $\chi, \xi>0$. The elasticity of labor supply is $\eta=(1-\sigma) /(\xi+\sigma)>$ 0 , and the equilibrium real wage in the competitive equilibrium-given firms' aggregate labor demand-can be written as

$$
\omega(L)=\chi^{1 /(1-\sigma)} L^{1 / \eta}
$$

with elasticities

$$
\frac{\omega^{\prime} L}{\omega}=\frac{1}{\eta} \quad \text { and } \quad E_{\omega^{\prime}}=1-\frac{1}{\eta}<1 .
$$

The production function is $F\left(L_{j}\right)=A L_{j}^{\alpha}$, where $A>0,0<\alpha \leq 1$, and returns are nonincreasing.

The objective function of each firm is strictly concave, and so Proposition 1 applies. It is easily checked that total employment under the unique symmetric equilibrium is

$$
L^{*}=\left(\chi^{-1 /(1-\sigma)} J^{1-\alpha} \frac{A \alpha}{1+H / \eta}\right)^{1 /(1-\alpha+1 / \eta)} .
$$

Figure 1 illustrates that an increase in common ownership-that is, an increase in $\phi$ or a decrease in the number of firms-reduces equilibrium employment and real wages.

\footnotetext{
${ }^{22}$ In contrast to the partial equilibrium model of Farrell (1985), the equilibrium markdown in our modelbecause of the labor market power effect-is not zero even when ownership is proportional to consumption. If the labor market is competitive (i.e., if $\eta=\infty$ ), then the equilibrium markdown is zero. See also Mas-Colell and Silvestre (1991).
} 


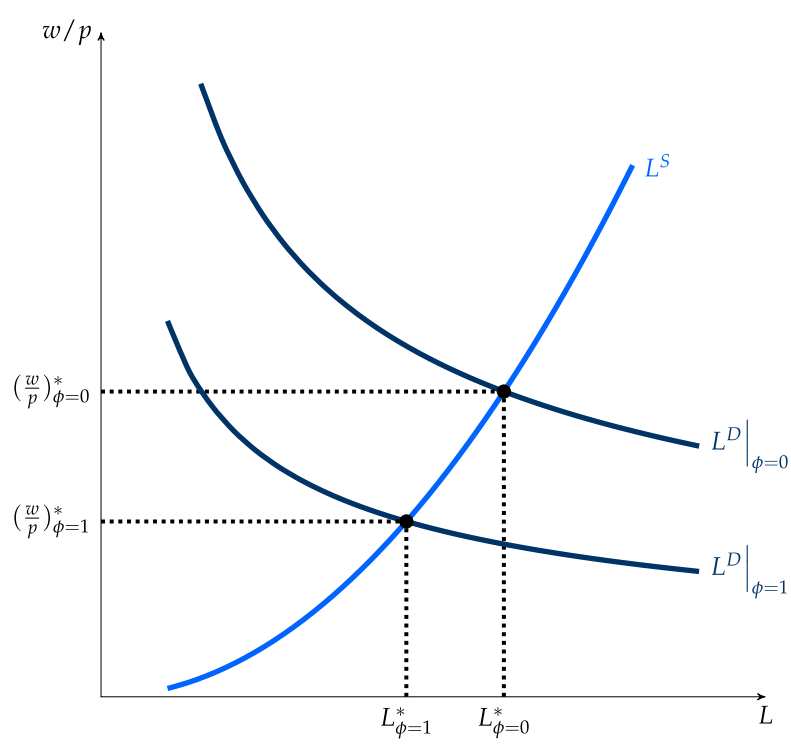

FIGURE 1.-Effect of an increase in market concentration on equilibrium real wages and employment in the one-sector model. The model parameters for the plot are: $A=6, J=4, \alpha=0.5, \xi=0.5, \sigma=0.5$, and $\chi=0.5$. When $\phi=0$, the MHHI is $H=0.25$; when $\phi=1$, the MHHI is $H=1$. Here $L^{S}$ refers to the labor supply curve and $L^{D}$ refers to the curve defined by the firm's first-order condition while imposing symmetry.

With increasing returns to scale, however, reducing the number of firms involves a tradeoff between market power and efficiency. In that case, a decline in the number of firms can increase real wages under some conditions.

The symmetric equilibrium is locally stable if $\alpha-1<(1-\lambda)(J \eta)^{-1}(1+H / \eta)^{-1}$, which means that a range of increasing returns may be allowed provided that an equilibrium exists. If $\alpha>1$, then neither the inequality $-F^{\prime \prime}+(1-\lambda) \omega^{\prime}>0$ nor the payoff global concavity condition need hold. In Appendix B, we characterize the case where $\alpha \in(1,2)$ and $\eta \leq 1$ and then give a necessary and sufficient condition for an interior symmetric equilibrium to exist when returns are increasing. Under that condition, $L^{*}$ is decreasing in $\phi$; yet it may either increase or decrease with $J$ depending on whether the effect on the markdown or the economies of scale prevail.

\subsection{Heterogeneous Firms}

When firms have access to different constant returns to scale technologies (CRS), we confirm the results in Proposition 1 and establish a positive association between common ownership and the dispersion of market shares.

PROPOSITION 2: Let $E_{\omega^{\prime}}<1$ and firms have potentially different CRS technologies with $F_{j}\left(L_{j}\right)=A_{j} L_{j}, A_{j}>0, j=1, \ldots, J$. Then an equilibrium exists and is unique with $\lambda<1$. In an interior equilibrium with $L^{*} \in(0, T)$, the following statements hold:

(a) The markdown of real wages for firm $j$ is given by

$$
\mu_{j} \equiv \frac{F_{j}^{\prime}\left(L_{j}^{*}\right)-\omega\left(L^{*}\right)}{\omega\left(L^{*}\right)}=\frac{s_{j}^{*}+\lambda\left(1-s_{j}^{*}\right)}{\eta\left(L^{*}\right)},
$$


where $s_{j}^{*} \equiv L_{j}^{*} / L^{*}$ and where the weighted average markdown is

$$
\bar{\mu} \equiv \sum_{j=1}^{J} s_{j} \mu_{j}=\frac{H}{\eta\left(L^{*}\right)} ;
$$

here $H=\mathrm{HHI}(1-\lambda)+\lambda$ is the modified $H H I$, and both $H$ and $\bar{\mu}$ are increasing in $\phi$.

(b) The total employment level $L^{*}$ and the real wage $\omega^{*}$ are each decreasing in $\phi$.

(c) The share of income going to workers, $\left(\omega\left(L^{*}\right) L^{*}\right) /\left(J F\left(L^{*} / J\right)\right)=1 /(1+\bar{\mu})$, decreases with $\phi$.

(d) If technologies are heterogeneous, then: (a) both the HHI and the minimal relative productivity for the least productive firm to be viable (i.e., $A_{\min } / \bar{A}$, where $\bar{A}=\sum_{j=1}^{J} A_{j} / J$ ) are increasing in $\phi$; and (b) only the most productive firm is active when $\phi \rightarrow 1$.

Thus, under firm heterogeneity, an increase in common ownership as measured by $\phi$ (and $\lambda$ ) leads endogenously to an increase in the Herfindahl-Hirschman index. This follows because a firm's market share $s_{j}$ increases (resp. decreases) when $\lambda$ increases if $j$ has above-average (resp. below-average) productivity. The implication is that, when common ownership increases, the variance of $s_{j}$ increases and so the HHI increases as well. The effect of common ownership is similar to the behavior of a multi-plant monopolist who shifts production toward the more efficient plants. ${ }^{23}$ Common ownership thus generates a re-allocation of market share from low-productivity, low-markup, high-labor share firms to high-productivity, high-markup, low-labor share firms. As stated in Section 2.2, a pattern of re-allocation from low- to high-markup U.S. firms in recent decades was documented by De Loecker, Eeckhout, and Unger (2020), and Autor et al. (2020) and Kehrig and Vincent (2018) both found evidence of a re-allocation from high-labor share to low-labor share firms.

REMARK: At a Cournot interior equilibrium with constant marginal costs, total output does not depend on the distribution of costs (e.g., Bergstrom and Varian (1985)). Here, too, we have that total employment depends only on average productivity $\bar{A}=\sum_{j=1}^{J} A_{j} / J$ and not on its variance. However, a technological change that induces a discrete increase in the dispersion of productivities, large enough to induce the exit of inefficient firms from the market, does affect equilibrium employment. In addition, an increase in common ownership may reinforce this effect. Indeed, we can show that the minimal relative productivity for the least productive firm to be viable $\left(A_{\min } / \bar{A}\right)$ is given by $\frac{(\eta+\lambda) /(1-\lambda)}{(\eta+\lambda) /(1-\lambda)+1 / J}$, which is increasing in $\lambda .^{24}$ Moreover, if it is not profitable for the $j$ th least productive firm to produce a positive amount in equilibrium, then it is also not profitable to produce with $\lambda^{\prime}>\lambda$. As $\phi \rightarrow 1$, only the most productive firm survives and behaves like a monopsonist.

\subsection{Summary and Investment Extension}

So far, we have shown that the simple model developed in this section can help make sense of some recent macroeconomic stylized facts-including persistently low output,

\footnotetext{
${ }^{23}$ It follows that increases in common ownership will raise the relative incentives of the more efficient firms to invest in cost reduction - that is, since they will end up producing more (see the model in López and Vives (2019)).

${ }^{24}$ To see that the threshold is increasing in $\lambda$, we use Lemma 1 in Appendix B, which shows that, in equilibrium, $\frac{\partial \eta}{\partial \lambda}+1>0$.
} 
employment, and wages in the presence of high corporate profits and financial wealthas a response to a permanent increase in effective concentration (due either to common ownership or to a reduced number of competitors). Because we have yet to incorporate investment decisions into the model, there is no real interest rate and so we have nothing to say about how it is affected. Even so, the model can be extended to include saving, capital, investment, and the real interest rate. In Azar and Vives (2019a), we presented a model with workers, owners, and savers and showed that-for investors who are not fully diversified-either a fall in the number $J$ of firms or a rise in $\phi$, the common ownership parameter, will lead to an equilibrium with lower levels of capital stock, employment, real interest rate, real wages, output, and labor share of income. Under certain (reasonable) conditions, the changes just described will lead also to a declining capital share.

When firms are large relative to the economy, an increase in market power implies that firms have an incentive to reduce both their employment and investment below the competitive level; this follows because, even though such firms sacrifice in terms of output, they benefit from lower wages and lower interest rates on every unit of labor and capital that they employ. The effect described here is present only when firms' shareholders perceive that they can affect the economy's equilibrium level of real wages and real interest rates by changing their production plans. Thus, when oligopolistic firms have market power over the economy as a whole, their owners can extract rents from both workers and savers. ${ }^{25}$

\section{MULTIPLE SECTORS}

In this section, we extend the model to multiple sectors in a Cobb-Douglas isoelastic environment. We characterize the equilibrium, uncover new and richer comparative statics results, and proceed to analyze large markets and convergence to the monopolistic competition outcome as the number of sectors grows large. We end the section with a note on calibration of the model.

\subsection{Model Setup}

Consider an economy with $N$ sectors, each offering a different consumer product. We assume that both the mass of workers and the mass of owners are equal to $N$. So as we scale the economy by increasing the number of sectors, the number of people in the economy scales proportionally. The utility function of worker $i$ is as in the additively separable isoelastic model: $U\left(C_{i}, L_{i}\right)=C_{i}^{1-\sigma} /(1-\sigma)-\chi L_{i}^{1+\xi} /(1+\xi)$ for $\sigma \in(0,1)$ and $\chi, \xi>0$, where

$$
C_{i}=\left[\left(\frac{1}{N}\right)^{1 / \theta} \sum_{n=1}^{N} c_{n i}^{(\theta-1) / \theta}\right]^{\theta /(\theta-1)} ;
$$

here, $c_{n i}$ is the consumption of worker $i$ in sector $n$, and $\theta>1$ is the elasticity of substitution indicating a preference for variety. ${ }^{26}$

\footnotetext{
${ }^{25}$ Our model does not account for the possibility of inter-firm technological spillovers due to investment. López and Vives (2019) showed that, if spillovers are high enough, then increased common ownership may boost R\&D investment as well.

${ }^{26}$ The form of $C_{i}$ is the one used by Allen and Arkolakis (2016). The weight $(1 / N)^{1 / \theta}$ in $C_{i}$ implies that, as $N$ grows, the indirect utility derived from $C_{i}$ does not grow unboundedly and is consistent with a continuum
} 
For each product, there are $J$ firms that can produce it using labor as input. The profits of firm $j$ in sector $n$ are given by

$$
\pi_{n j}=p_{n} F\left(L_{n j}\right)-w L_{n j}
$$

here, the production function is $F\left(L_{n j}\right)=A L_{n j}^{\alpha}$ with $A>0$ and $\alpha>0$.

The ownership structure is similar to the single-sector case, except that now (i) there are $J \times N$ groups of shareholders and (ii) shareholders can diversify both in an industry fund and in an economy-wide fund. Group $n j$ owns a fraction $1-\phi-\widetilde{\phi} \geq 0$ in firm $n j$ directly, an industry index fund with a fraction $\widetilde{\phi} / J$ in every firm in sector $n$, and an economywide index fund with a fraction $\phi / N J$ in every firm. The owners' utility is simply their consumption $C_{i}$ of the composite good. Solving the owners' utility maximization problem yields the indirect utility function of shareholder $i$ (i.e., $V\left(P, w ; W_{i}\right)=W_{i} / P$ ) when prices are $\left\{p_{n}\right\}_{n=1}^{N}$, the level of wages is $w$, shareholder wealth is $W_{i}$, and $P \equiv\left(\frac{1}{N} \sum_{n=1}^{N} p_{n}^{1-\theta}\right)^{1 /(1-\theta)}$ is the price index.

The objective function of the manager of firm $j$ in sector $n$ is to choose the firm's level of employment, $L_{n j}$, that maximizes a weighted average of shareholder (indirect) utilities. By rearranging coefficients so that the coefficient for own profits equals 1 , we obtain the objective function

$$
\underbrace{\frac{\pi_{n j}}{P}}_{\text {own profits }}+\lambda_{\text {intra }} \underbrace{\sum_{k \neq j} \frac{\pi_{n k}}{P}}_{\text {industry } n \text { profits, other firms }}+\lambda_{\text {inter }} \underbrace{\sum_{m \neq n} \sum_{k=1}^{J} \frac{\pi_{m k}}{P}}_{\text {profits, other industries }},
$$

where the lambdas are a function of $(\phi, \widetilde{\phi}, J, N)$.

Thus the firm accounts for the effects of its actions not only on same-sector rivals but also on firms in other sectors. Note that the manager's objective function depends on $N+1$ relative prices-that is, on $w / P$ in addition to $\left\{p_{n} / P\right\}_{n=1}^{N}$ for $N>1$.

We can show that the Edgeworth sympathy coefficient for other firms in the same sector as the focal firm is

$$
\lambda_{\text {intra }}=\frac{(2-\phi) \phi+[2(1-\phi)-\widetilde{\phi}] \widetilde{\phi} N}{(1-\phi)^{2} J N+(2-\phi) \phi-[2(1-\phi)-\widetilde{\phi}] \widetilde{\phi} N(J-1)}
$$

and that the Edgeworth sympathy coefficient for firms in other sectors is given by

$$
\lambda_{\text {inter }}=\frac{(2-\phi) \phi}{(1-\phi)^{2} J N+(2-\phi) \phi-[2(1-\phi)-\widetilde{\phi}] \widetilde{\phi} N(J-1)} .
$$

Observe that $\lambda_{\text {intra }}$ is no less than $\lambda_{\text {inter }}$. This follows because the former sums the profit weights of both the industry fund and the economy-wide fund. We can show (see Lemma 2 in Appendix B) that $\lambda_{\text {intra }}$ and $\lambda_{\text {inter }}$ are always in [0,1], increasing in $\phi$ and $\widetilde{\phi}$, and-for $\phi>0$ and $\phi+\widetilde{\phi}<1$-decreasing in $N$ and $J$.

When $\phi+\widetilde{\phi}=1$, we have $\lambda_{\text {intra }}=1$ and $\lambda_{\text {inter }}=\left(1-\widetilde{\phi}^{2}\right) /\left[1+\widetilde{\phi}^{2}(N-1)\right]$; as a result, if agents are fully invested in the two index funds, then $\lambda_{\text {intra }}=1$ regardless of the share

formulation for the sectors (replacing the summation with an integral) of unit mass. More precisely: if the equilibrium is symmetric, then, regardless of $N$, the level of consumption $C_{i}$ is equal to the consumer's income divided by the price. 
in each fund. In contrast, the sympathy $\lambda_{\text {inter }}$ for firms in other sectors decreases as shares are moved from the economy index fund to the own-industry index fund $\widetilde{\phi} \cdot{ }^{27}$ Indeed, if everything is invested in the industry fund, then $\widetilde{\phi}=1, \lambda_{\text {intra }}=1$, and $\lambda_{\text {inter }}=0$. If there is no economy-wide index fund, then $\phi=0, \lambda_{\text {inter }}=0$, and $\lambda_{\text {intra }}=\frac{(2-\widetilde{\phi} \widetilde{\phi}}{(1-\widetilde{\phi})^{2} J+(2-\tilde{\phi})}$. If there are no industry funds, then $\widetilde{\phi}=0$ and $\lambda_{\text {intra }}=\lambda_{\text {inter }}=\frac{(2-\phi) \phi}{(1-\phi)^{2} J N+(2-\phi) \phi} \cdot{ }^{28}$ Finally, if everything is invested in the economy-wide index fund, then $\phi=1$ and $\lambda_{\text {intra }}=\lambda_{\text {inter }}=1$.

\subsection{Cournot-Walras Equilibrium With N Sectors}

We start by characterizing the competitive equilibrium in terms of relative prices $w / P$ and of $\left\{p_{n} / P\right\}_{n=1}^{N}$, given the production plans of the $J$ firms operating in the $N$ sectors: $\mathbf{L} \equiv\left\{\mathbf{L}_{1}, \ldots, \mathbf{L}_{J}\right\}$, where $\mathbf{L}_{j} \equiv\left(L_{1 j}, \ldots, L_{N j}\right)$. Then we characterize the equilibrium in the plans of the firms.

\subsubsection{Relative Prices in a Competitive Equilibrium Given Firms' Production Plans}

Because the function that aggregates the consumption of all sectors is homothetic, workers face a two-stage budgeting problem. First, workers choose their consumption across sectors (conditional on their aggregate level of consumption) to minimize expenditures; second, they choose labor supply $L_{i}$ and consumption level $C_{i}$ to maximize their utility $U\left(C_{i}, L_{i}\right)$ subject to the budget constraint $P C_{i}=w L_{i}$, where $P$ is the price index.

We can therefore write the first-stage problem as

$$
\min _{\left\{c_{n i}\right\}_{n=1}^{N}} \sum_{n=1}^{N} p_{n} c_{n i}
$$

subject to

$$
\left[\sum_{n=1}^{N}\left(\frac{1}{N}\right)^{1 / \theta} c_{n i}^{(\theta-1) / \theta}\right]^{\theta /(\theta-1)}=C_{i} .
$$

The solution to this problem yields the standard demand of consumer $i$ for each product $n$ conditional on aggregate consumption $C_{i}$ :

$$
c_{n i}=\frac{1}{N}\left(\frac{p_{n}}{P}\right)^{-\theta} C_{i} .
$$

It follows from homotheticity that, for every consumer, total expenditures equal the price index multiplied by their respective level of consumption:

$$
\sum_{n=1}^{N} p_{n} c_{n i}=P C_{i}
$$

\footnotetext{
${ }^{27}$ When $\phi+\widetilde{\phi}=1$, two firms in the same industry have the same ownership structure, each with $\phi$ and $\widetilde{\phi}$ proportions of each fund. Therefore, there is shareholder unanimity in maximizing joint industry profits and $\lambda_{\text {intra }}=1$.

${ }^{28}$ In both cases, $\lambda$ is given as in the one-sector economy: in the first case with $\widetilde{\phi}$ instead of $\phi$, and in the second with $J N$ instead of $J$.
} 
In the second stage, the first-order condition for an interior solution is given by

$$
\frac{w}{P}=-\frac{U_{L}\left(\frac{w}{P} L_{i}, L_{i}\right)}{U_{C}\left(\frac{w}{P} L_{i}, L_{i}\right)} .
$$

Since workers are homogeneous, it follows that total labor supply $\int_{i \in I} L_{i} d i$ is simply $N$ times the individual labor supply $L_{i}$; moreover, because total labor demand $L$ must equal total labor supply, equation (4.2) implicitly defines the equilibrium real wage (now relative to the price of the composite good) as a function $\omega(L)$ of the firms' total employment plans. We retain the assumptions for increasing labor supply that ensure $\omega^{\prime}>0$. Then $\omega(L)=\chi^{1 /(1-\sigma)}(L / N)^{1 / \eta}$, where again $\eta=(1-\sigma) /(\xi+\sigma)$ is the elasticity of labor supply.

Shareholders maximize their aggregate consumption level conditional on their income. Their consumer demands, conditional on their respective levels of consumption, are identical to those of workers. Adding up the demands across owners and workers, we obtain

$$
\underbrace{\int_{i \in I_{W} \cup I_{O}} c_{n i} d i}_{c_{n}}=\frac{1}{N}\left(\frac{p_{n}}{P}\right)^{-\theta} \underbrace{\int_{i \in I_{W} \cup I_{O}} C_{i} d i}_{C} .
$$

In a competitive equilibrium, consumption demand must equal the sum of all firms' production of each product:

$$
c_{n}=\sum_{j=1}^{J} F\left(L_{n j}\right)
$$

Using equation (4.1) and integrating across consumers, we have that $c_{n}=\frac{1}{N}\left(\frac{p_{n}}{P}\right)^{-\theta} C$. So given firms' production plans, the following equality holds in a competitive equilibrium:

$$
\frac{p_{n}}{P}=\left(\frac{1}{N}\right)^{1 / \theta}\left(\frac{c_{n}}{C}\right)^{-1 / \theta}
$$

The elasticity of the relative price of sector $n, p_{n} / P$, with respect to the aggregate production $c_{n}$ of the sector for given production in the other sectors $\left(c_{m}\right.$ for $\left.m \neq n\right)$, when evaluated at a symmetric equilibrium, is $-(1-1 / N) / \theta$. Its absolute value is decreasing in the elasticity of substitution of the varieties $(\theta)$ and increasing in the number of sectors $(N)$. Increasing $c_{n}$ has a direct negative impact on $p_{n} / P$ of $-1 / \theta$ for a given $C$, and an indirect positive impact on $p_{n} / P$ by increasing aggregate real income $C$, yielding $1 /(\theta N)$. When there is only one sector $(N=1)$, there is obviously no impact on the relative price. Furthermore, the overall effect increases with the number $N$ of sectors because then the indirect effect is weaker. 
We can now use equations (4.3) and (4.4) to obtain an expression for $\rho_{n} \equiv p_{n} / P$ in a competitive equilibrium conditional on firms' production plans $\mathbf{L}$ :

$$
\rho_{n}(\mathbf{L})=\left(\frac{1}{N}\right)^{1 / \theta}\left\{\frac{\sum_{j=1}^{J} F\left(L_{n j}\right)}{\left[\sum_{m=1}^{N}\left(\frac{1}{N}\right)^{1 / \theta}\left(\sum_{j=1}^{J} F\left(L_{m j}\right)\right)^{(\theta-1) / \theta}\right]^{\theta /(\theta-1)}}\right\}^{-1 / \theta} .
$$

Observe that - unlike the previous case of a real-wage function, where the dependence was only through total employment plans-relative prices under a competitive equilibrium depend directly on the employment plans of each individual firm.

PROPOSITION 3: Given the production plans $\mathbf{L} \equiv\left\{L_{m j}\right\}$ of firms with aggregate labor demand $L$, the competitive equilibrium is given by the real wage $\omega(L)$ and the relative prices of the $N$ sectors: $\rho_{n}(\mathbf{L})$ for $n=1, \ldots, N$. If firm $j$ in sector $n$ expands its employment plans, then $\omega$ increases; in addition, $\rho_{n}$ decreases $\left(\partial \rho_{n} / \partial L_{n j}<0\right)$ while $\rho_{m}, m \neq n$, increases $\left(\partial \rho_{m} / \partial L_{n j}>0\right)$.

An increase in employment by a firm in sector $n$ increases the relative supply of the consumption good of that sector relative to other sectors, thereby reducing the relative price of the focal sector's good. Since this increased employment increases overall supply of the aggregate consumption good while leaving supply of the other sectors unchanged, the relative prices of goods in those other sectors increase.

\subsubsection{Cournot-Walras Equilibrium}

The optimization problem of firm $j$ in sector $n$ is given by

$$
\max _{L_{n j}}\{\underbrace{\frac{\pi_{n j}}{P}}_{\text {own profits }}+\lambda \underbrace{\sum_{k \neq j} \frac{\pi_{n k}}{P}}_{\text {industry } n \text { profits, other firms }}+\lambda \underbrace{\sum_{m \neq n} \sum_{k=1}^{J} \frac{\pi_{m k}}{P}}_{\text {profits, other industries }}\},
$$

where $\pi_{n j} / P=\rho_{n} F\left(L_{n j}\right)-\omega(L) L_{n j}$. The first-order condition for the firm is

$$
\begin{gathered}
\underbrace{\rho_{n}(\mathbf{L}) F^{\prime}\left(L_{n j}\right)}_{\text {VMPL }}-\underbrace{\omega(L)}_{\text {real wage }}-\underbrace{\frac{\partial \omega}{\partial L_{n j}}\left[L_{n j}+\lambda \sum_{k \neq j} L_{n k}+\lambda \sum_{m \neq n} \sum_{k=1}^{J} L_{m k}\right]}_{\text {(i) wage effect }} \\
+\underbrace{\frac{\partial \rho_{n}}{\partial L_{n j}}\left[F\left(L_{n j}\right)+\lambda \sum_{k \neq j} F\left(L_{n k}\right)\right]}_{\text {(ii) own-industry relative price effect }}+\underbrace{\lambda \sum_{m \neq n} \frac{\partial \rho_{m}}{\partial L_{n j}}\left[\sum_{k=1}^{J} F\left(L_{m k}\right)\right]}_{\text {(iii) other industries' relative price effect }}=0 .
\end{gathered}
$$

When a firm in a given sector considers hiring an additional worker, it faces the following trade-offs. On the one hand, expanding employment increases profits by the value of 
the marginal product of labor (VMPL), which the shareholders can consume after paying the new workers the real wage. On the other hand, expanding employment will increase real wages for all workers because the labor supply is upward sloping. So when there is common ownership, the owners will take into account the wage effect not just for the firm that expands employment (or just for the firms in the same industry) but for all firms in all industries. Furthermore, expanding employment will increase output in the firm's sector and thereby reduce that sector's relative prices; as before, owners internalize that reduction not just for the firm itself but for all firms in the sector in which they have common ownership. Finally, expanding output in the firm's sector decreases consumption in all the other sectors and thus increases their relative prices; the owners of the firm, if they have common ownership involving other sectors, internalize these increased relative prices as a positive pecuniary externality.

As we establish in Appendix B, a firm's objective function is strictly concave if $\alpha \leq 1$. We therefore have the following existence and characterization result. ${ }^{29}$

PROPOSITION 4: Consider a multi-sector economy with additive separable isoelastic preferences and a Cobb-Douglas production function under non-increasing returns to scale $(\alpha \leq 1)$. There exists a unique symmetric equilibrium, and equilibrium employment is given by

$$
L^{*}=N\left(J^{1-\alpha} \frac{\chi^{-1 /(1-\sigma)} A \alpha}{1+\mu^{*}}\right)^{1 /(1-\alpha+1 / \eta)} .
$$

The equilibrium markdown of real wages is

$$
\mu^{*}=\frac{1+H_{\text {labor }} / \eta}{1-\left(H_{\text {product }}-\lambda_{\text {inter }}\right)(1-1 / N) / \theta}-1,
$$

where $H_{\text {labor }} \equiv\left(1+\lambda_{\text {intra }}(J-1)+\lambda_{\text {inter }}(N-1) J\right) / N J$ is the modified HHI of the labor market and $H_{\text {product }} \equiv\left(1+\lambda_{\text {intra }}(J-1)\right) / J$ is the modified HHI for each sector.

The markdown $\mu^{*}$ decreases with $J\left(\right.$ for $\phi+\widetilde{\phi}<1$, with $\mu^{*} \rightarrow 0$ as $\left.J \rightarrow \infty\right)$, $\eta$, and $\theta$ (for $\phi<1)$; it increases with $\widetilde{\phi}$; and it can be non-monotone in $\phi$.

If $\widetilde{\phi}=0$ (no industry fund, $\lambda_{\text {intra }}=\lambda_{\text {inter }}=\lambda$ ), then $H_{\text {product }}-\lambda=(1-\lambda) / J$ and

$$
\operatorname{sgn}\left\{\frac{\partial \mu^{*}}{\partial \phi}\right\}=\operatorname{sgn}\left\{\frac{\theta}{1+\eta}-\frac{N-1}{J N-1}\right\} .
$$

REMARK: Simulations reveal that $\mu^{*}$ may be non-monotone in $\phi$ also if $\widetilde{\phi}>0$. In fact, we can show that if $\eta$ is large enough, then $\mu^{*}$ is decreasing in $\phi$ for $\widetilde{\phi}>0$ small and increasing in $\phi$ for $J N$ large. Furthermore, $\mu^{*}$ is found to be either increasing or decreasing in $N$.

In the multiple-industry case, we find that the equilibrium real wage, employment, and output are analogous - as a function of the markdown - to those in the single-industry case. The only difference is that the markdown is now more complicated owing to the existence of multiple sectors and of product differentiation across firms in different sectors.

\footnotetext{
${ }^{29} \mathrm{As}$ in the one-sector case, if $\phi=1$ and $\alpha=1$, then there is a unique symmetric equilibrium and there also exist asymmetric equilibria, since shareholders are indifferent to which firms employ the workers as long as total employment is at the monopoly level.
} 
An important result that contrasts with the single-sector case is that employment, output, and the real wage may all increase with diversification using the economy-wide fund $\phi$.

Perfect Substitutes. As the elasticity of substitution $(\theta)$ tends to infinity, the products of the different sectors become close to perfect substitutes; then the equilibrium is just as in the one-industry case but with $J N$ firms instead of $J$ firms. This outcome should not be surprising given that, in the case of perfect substitutes, all firms produce the same good and so-for all intents and purposes-there is but a single industry in the economy.

The Two Wedges of the Markdown. The markdown of wages below the marginal product of labor can be viewed as consisting of two "wedges," one reflecting labor market power and one reflecting product market power. In particular, the labor market wedge is $1+H_{\text {labor }} / \eta$. The markdown is increasing in $H_{\text {labor }} / \eta$, which reflects the level of labor market power (and so decreases with $J N$ and $\eta$ ). The product market wedge is ( $H_{\text {product }}-$ $\left.\lambda_{\text {inter }}\right)(1-1 / N) / \theta$. This wedge has two components: the first is $H_{\text {product }}(1-1 / N) / \theta$, reflecting the level of market power in the firm's sector; the second is $\lambda_{\text {inter }}(1-1 / N) / \theta$, reflecting the inter-sectoral externality (note that the latter diminishes as products become more substitutable and $\theta$ increases). The markdown is increasing in the first component of the product market wedge, and decreasing in the second component. ${ }^{30}$

From the previous paragraph, it follows that $\mu^{*}$ is positively associated with $\lambda_{\text {intra }}$ because so also are both the labor and product wedges - that is, since $H_{\text {labor }}$ and $H_{\text {product }}$ are increasing in $\lambda_{\text {intra }}$. However, $\mu^{*}$ may be positively or negatively associated with $\lambda_{\text {inter }}$ because, when $\lambda_{\text {inter }}>0$, we must account for the effect of expanding employment (by firm $j$ in sector $n$ ) on the profits of other firms. Expanding employment in one sector benefits firms in other sectors by increasing the relative prices in those sectors (pecuniary externality) via the increase in overall consumption generated by firm $n j$ 's expanded employment plans. The result is that $H_{\text {product }}$ is then reduced by $\lambda_{\text {inter }}$ (note that $H_{\text {product }} \geq \lambda_{\text {inter }}$ always). If an increase in $\lambda_{\text {inter }}$ increases the labor market wedge more than it reduces the product market wedge, then $\mu^{*}$ is decreasing in $\underset{\sim}{\lambda_{\text {inter }}}$; the converse of this statement holds as well.

Case With No Industry Fund. When $\widetilde{\phi}=0$, we have $\lambda_{\text {intra }}=\lambda_{\text {inter }}=\lambda$; then the net effect of an increase in $\lambda$ (due to an increase in $\phi$ ) will be to diminish the product market wedge. To see this, note that $\left(H_{\text {product }}-\lambda\right)(1-1 / N) / \theta=(1-\lambda)(1-1 / N) /(\theta J)$. In the limit, when $\phi=1$ and $\lambda=1$, we have a cartel or a monopoly and the two product market effects cancel each other out exactly. ${ }^{31}$ It is worth noting that $\mu^{*}$ may either increase or decrease with portfolio diversification $\phi$ depending on whether labor market effects or rather product market effects prevail. The markdown will be decreasing in $\phi$ when the increase in the labor market wedge (due to the higher $\phi$ ) is more than compensated by the lower product market wedge (due to the pro-competitive inter-sectoral pecuniary externality) - in other words, when the effect of profit internalization on the level of market power in product markets is higher than it is in the labor market. This happens when the elasticity of substitution $\theta$ is small in relation to the elasticity of labor supply $\eta$. When $\eta \rightarrow \infty$, common ownership always has a pro-competitive effect. If $N$ is large, then the

\footnotetext{
${ }^{30}$ Recall that, when evaluated at a symmetric equilibrium, the (absolute value of the) elasticity of "inverse demand" $p_{n} / P$ with respect to $c_{n}$ is $(1-1 / N) / \theta$; this explains why $H_{\text {product }}(1-1 / N) / \theta$ is the indicator of product market power (note that this indicator decreases with $J$ and $\theta$ but increases with $N$ ).

${ }^{31}$ When portfolios are perfectly diversified $(\phi=1)$, the economy can be viewed as consisting of a single large firm that produces the composite good. Since the owner-consumers own shares in each of the components of the composite good in the same proportion and since they use profits only to purchase that good, these ownerconsumers are to the same extent shareholders and consumers of the composite good. So just as in the singlesector economy, the effects cancel out exactly. The $N=1$ case is the one-sector model developed in Section 3 . Here $\lambda=1$ can be understood in similar terms except that, in this case, there is an aggregate good $C$.
} 
anti-competitive effect of common ownership prevails provided that $\eta<1$. This outcome follows because then $\theta /(1+\eta)>1 / 2$ and

$$
\operatorname{sgn}\left\{\frac{\partial \mu^{*}}{\partial \phi}\right\}=\operatorname{sgn}\left\{\frac{\theta}{1+\eta}-\frac{1}{J}\right\}>0 .
$$

Under the parameter configurations for the elasticities considered in Azar and Vives (2019a), $\theta=3$ and with a conservative $\eta=0.6$, we have that $\frac{\theta}{1+\eta}>\frac{1}{2}$. In consequence, the anti-competitive effect will prevail for $N$ large.

\subsection{Large Economies}

Most of the literature on oligopoly in general equilibrium considers the case of an infinite number of sectors such that each sector, and therefore each firm, is small relative to the economy. Monopolistic competition can be viewed as a special case of a model with infinite sectors in which there is only one firm per industry. Here we consider what happens when the number of sectors, $N$, tends to infinity. Our aim is to identify the conditions under which the monopolistically competitive limit is obtained (as in Dixit and Stiglitz (1977)). We consider the following cases where owners: (i) hold fully diversified portfolios, (ii) are not diversified, (iii) are fully diversified only intra-industry for $N$ large, and (iv) are fully diversified for $N$ large.

\subsubsection{Case 1: Full Diversification $(\phi=1, \widetilde{\phi}=0)$}

When all the owner-consumers hold market portfolios, $\lambda_{\operatorname{intra}(N)}=\lambda_{\operatorname{inter}(N)}=1$. This means that we have a sequence of economies with an increasing number of sectors and firms but in which the equilibrium outcome remains the same. The product market wedge disappears because the owner-consumers fully internalize the effect of firms' decisions on themselves as consumers. As with the one-sector model, the labor market wedge remains at the monopsony level-here, because owner-consumers still have an incentive to reduce the real wages of worker-consumers. We remark that, if the model had a representative agent rather than owner-consumers and worker-consumers, then the labor market wedge would also disappear and the equilibrium would be efficient.

\subsubsection{Case 2: No Diversification $(\phi=\widetilde{\phi}=0)$}

Consider now the case in which owner-consumers hold shares in only one firm. In this case, as the number of sectors tends to infinity, the labor market wedge disappears as the number of firms interacting in the labor market goes to infinity (this result would not hold if the labor markets were segmented, for example, by industry). With $J>1$ firms, the limit economy is equivalent to that of Neary (2003b): a continuum of sectors, no labor market power, and a homogeneous-goods Cournot equilibrium in each sector (if goods were heterogeneous within sector, then the limit economy would be equivalent to that of Atkeson and Burstein (2008)). In the case of $J=1$, the limit economy in this case is equivalent to that of the Dixit and Stiglitz (1977) monopolistic competition model.

One must bear in mind, however, that obtaining these economies as a limit in the model requires heterogeneous agents: owner-consumers and worker-consumers; also, within the owner-consumers, there must be different groups with each group having ownership in just one firm. If, as in Neary (2003b), Atkeson and Burstein (2008), and Dixit and Stiglitz (1977), we assumed a representative agent: (a) there would be fully diversified ownerworker-consumers; and (b) the equilibrium of the economy at each point in the sequence 
of economies would be efficient, with price equal to marginal cost. Even though the models in these papers assume profit maximization, no shareholder would actually want the firms to maximize profits. This tension was discussed in Section 2.

\subsubsection{Case 3: Only Intra-Industry Asymptotic Diversification $\left(\phi=0, \widetilde{\phi}_{N} \rightarrow \widetilde{\phi}>0\right)$}

When $\phi=0$, oligopsony power vanishes in the limit because (again) the number of firms competing in the labor market goes to infinity and there is no inter-industry internalization effect $\left(\lambda_{\text {inter }(N)}=0\right)$. Thus, the limit economy is equivalent to that of Neary (2003b) but with horizontal, within-industry common ownership. In this case, for any $N$ we have the same formula as for the one-sector model except with $\widetilde{\phi}_{N}$ instead of $\phi$ :

$$
\lambda_{\operatorname{intra}(N)}=\frac{\left(2-\widetilde{\phi}_{N}\right) \widetilde{\phi}_{N}}{\left(1-\widetilde{\phi}_{N}\right)^{2} J+\left(2-\widetilde{\phi}_{N}\right) \widetilde{\phi}_{N}} .
$$

Here the markdown

$$
\mu_{N}^{*} \rightarrow \mu_{\infty}^{*}=\frac{1}{1-H_{\text {product }(\infty)} / \theta}-1
$$

increases with $\widetilde{\phi}$ when $J>1$ (in this formula, $H_{\text {product }(\infty)}$ refers to the limit product market modified HHI, which is $\left.1 / J+\lambda_{\text {intra }(\infty)}(1-1 / J)\right)$. If $\widetilde{\phi}=1$, then $H_{\text {product }(\infty)}=1$ and $\mu_{\infty}^{*}=$ $1 /(\theta-1)$.

Recall that the market power friction at a symmetric equilibrium can also be expressed in terms of the markup of product prices over the effective marginal cost of labor ( $\mathrm{mc} \equiv$ $\left.w / F^{\prime}(L / J N)\right)$,

$$
\tilde{\mu} \equiv \frac{p-\mathrm{mc}}{p}=\frac{\mu}{1+\mu},
$$

rather than in terms of the markdown. We have that $\tilde{\mu}^{*} \rightarrow 1 / \theta$ (the monopolistic competition markup of Dixit and Stiglitz (1977)) when there is essentially one firm per sector (either $J=1$ or $\lambda_{\text {intra }(\infty)}=1$; e.g., $\widetilde{\phi} \rightarrow 1$ ). ${ }^{32}$

\subsubsection{Case 4: Full Asymptotic Diversification $\left(\phi_{N} \rightarrow 1, \widetilde{\phi}=0\right)$}

We consider now the case with full asymptotic diversification $\left(\phi_{N} \rightarrow 1\right)$. For simplicity, we assume no industry fund: $\widetilde{\phi}=0$, where $\lambda_{\operatorname{intra}(N)}=\lambda_{\text {inter }(N)}=\lambda_{N}=\frac{\left(2-\phi_{N}\right) \phi_{N}}{\left(1-\phi_{N}\right)^{2} J N+\left(2-\phi_{N}\right) \phi_{N}}$. We start by observing that, if $\phi_{N} \rightarrow \phi<1$, then $\lambda_{N} \rightarrow 0$. This is so because, as the number of sectors in the economy increases: for a shareholder in group $n j$, the fraction held in each of the other firms (when $\phi$ is constant) is $\phi /(N J)$, which goes to zero, while the fraction $1-\phi+\phi /(N J)$ held in firm $n j$ does not. In this case, then, the equilibrium of

\footnotetext{
${ }^{32}$ Similar results are obtained with some economy-wide diversification. Suppose $\phi<1$ and $\widetilde{\phi}>0$ are fixed; then, as $N \rightarrow \infty$, we have that $\lambda_{\text {inter }} \rightarrow 0$ (and oligopsony power vanishes, since $\left.H_{\text {labor }} \rightarrow \lambda_{\text {inter }(\infty)}=0\right)$ but that

$$
\lambda_{\text {intra }} \rightarrow \lambda_{\text {intra }(\infty)} \equiv \frac{2 \gamma-1}{\gamma^{2} J-(2 \gamma-1)(J-1)},
$$

where $\gamma \equiv(1-\phi) / \widetilde{\phi}>0$ is the ratio of undiversified investment to investment in the industry fund. The parameter $\gamma$ ranges from 1 to infinity: $\gamma=1$ when $1-\phi=\widetilde{\phi}$ (e.g., as when $\widetilde{\phi}=1$ ); and $\gamma \rightarrow \infty$ as $\widetilde{\phi} \rightarrow 0$. If $\gamma=1$, then $\lambda_{\text {intra }(\infty)}=1$, and if $\gamma \rightarrow \infty$, then $\lambda_{\text {intra }(\infty)}=0$.
} 
the limit economy is like the one in Case 2 (no diversification); hence it is equivalent to Neary (2003b) when $J>1$ and to Dixit and Stiglitz (1977) when $J=1$.

Consider now the case when $\phi_{N} \rightarrow 1$, or, equivalently, $1-\phi_{N} \rightarrow 0$. In that case, the limit lambdas can take values between zero and 1, depending on the speed of convergence. In particular, to have $\lambda_{N} \rightarrow \lambda \in(0,1]$, we need the sequence $1-\phi_{N}$ to approach zero (full diversification) at least as rapidly as $1 / \sqrt{N}$ (i.e., $\sqrt{N}\left(1-\phi_{N}\right) \rightarrow k$ for $k \in[0, \infty))$. If the convergence rate is faster than $1 / \sqrt{N}$ with $k=0$, then the limiting $\lambda$ is always equal to 1 , and the equilibrium in the limit economy is the same as in Case 1 (full diversification). If the convergence rate is slower than $1 / \sqrt{N}$, then the limiting $\lambda$ is equal to zero, and the equilibrium in the limit economy is the same as in Case 2 (no diversification).

For sequences $1-\phi_{N}$ with convergence rates equal to $1 / \sqrt{N}$, the value of $\lambda$ in the limit is determined by $k$, the constant of convergence: if $\sqrt{N}\left(1-\phi_{N}\right) \rightarrow k$, then $\lim _{N \rightarrow \infty} \lambda_{N}=$ $1 /\left(1+J k^{2}\right) .{ }^{33}$ If $\lambda_{N} \rightarrow \lambda_{\infty}$, then the limit markdown is

$$
\mu_{\infty}^{*} \equiv \lim _{N \rightarrow \infty} \mu_{N}^{*}=\frac{1+\lambda_{\infty} / \eta}{1-\left(1-\lambda_{\infty}\right) /(\theta J)}-1 .
$$

The impact of $\lambda_{\infty}$ on the markdown depends, as before, on whether (or not) its effect on the labor market wedge effect dominates its effect on the product market wedge. The labor market wedge effect dominates the product market wedge effect if and only if the elasticity $\eta$ of labor supply is lower than $\theta J-1$. These results are summarized in our next proposition.

Proposition 5: Consider a sequence of economies $\left(\widetilde{\phi}_{N}, \phi_{N}, N\right)$, where $\widetilde{\phi}_{N}=0$ for all $N$ but attaining full diversification as $\phi_{N} \rightarrow 1$. If $\sqrt{N}\left(1-\phi_{N}\right) \rightarrow k$ for $k \in[0, \infty)$, then, as $N \rightarrow \infty$, we have $\lambda_{N} \rightarrow 1 /\left(1+J k^{2}\right)$-which is increasing in concentration $1 / J$ and in the speed of convergence of $\phi_{N} \rightarrow 1$ as measured by the constant $1 / k$. The limit markdown is $\mu_{\infty}^{*}=\left(1+\lambda_{\infty} / \eta\right) /\left(1-\left(1-\lambda_{\infty}\right) /(\theta J)\right)-1$, which is increasing in $\lambda_{\infty}$ if and only if $\theta /(1+\eta)>1 / J$ or $\theta J-1>\eta$.

That is to say: if full diversification is attained at least as fast as $1 / \sqrt{N}$ as the economy grows large, then profit internalization is (a) positive in the limit and (b) increasing both in concentration and in how rapidly diversification is achieved. The limit markdown increases with profit internalization if and only if $\theta /(1+\eta)>1 / J$.

Only when $\lambda_{\infty}=0$ do we obtain the markdown associated with the Dixit-Stiglitz or Neary $\mu_{\infty}^{*}=1 /(J \theta-1)$. When $\lambda_{\infty}>0$, however, we obtain a different limit. In this case, if $J \rightarrow \infty$, then there is no product market power and so the markdown $\lambda_{\infty} / \eta$ (i) is due only to labor market power and (ii) increases with $\lambda_{\infty}$. When $\eta \rightarrow \infty$, the labor market is competitive and the markdown is decreasing in $\lambda_{\infty}$. Finally, if $\lambda_{\infty}=1$, then we obtain the monopsony solution $\mu_{\infty}^{*}=1 / \eta$.

\footnotetext{
${ }^{33}$ This result follows from the expression for $\lambda_{N}$ by noting that $\left(1-\phi_{N}\right)^{2} N$ is of order $k^{2}$ and that $\phi_{N} \rightarrow 1$ as $N \rightarrow \infty$. Note that the limit sympathy coefficient $\lambda$ is increasing in market concentration $1 / J$ and also in the speed of convergence of $\phi_{N} \rightarrow 1$, as measured by the constant $1 / k$. When diversification increases faster ( $k$ smaller), profit internalization is larger. So in order for $\lambda$ to be positive, the limiting portfolio must be fully diversified: $\phi_{N} \rightarrow 1$. Indeed, if $\phi_{N}=1$ for all $N$, then also $\lambda_{N}=1$ for all $N$. If $\phi_{N}=1-\sqrt{(1-\lambda) /(\lambda J N+(1-\lambda))}$, then $\lambda$ is constant for all $N$.
} 


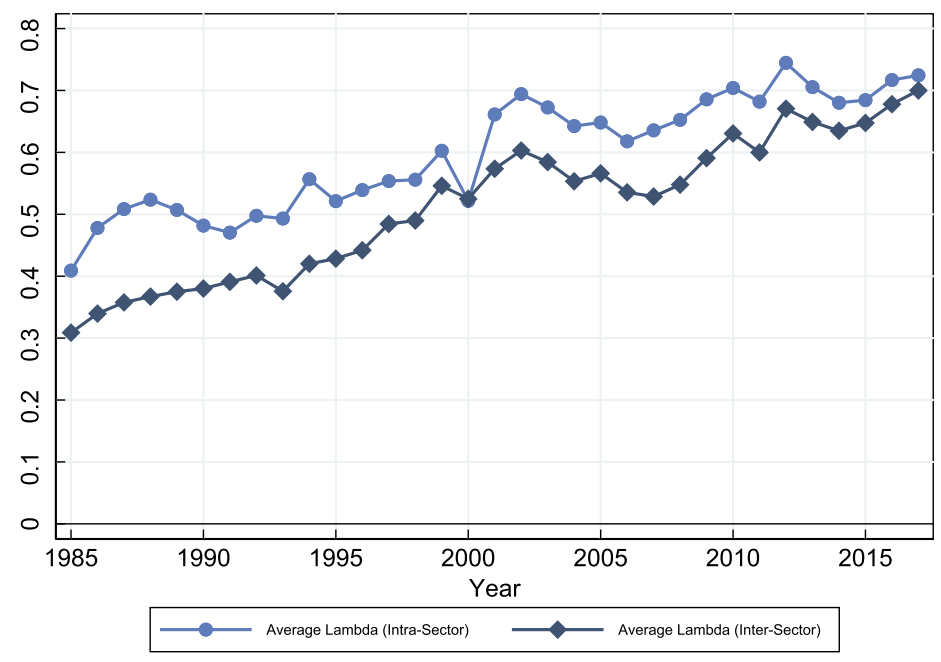

FIGURE 2.-Average intra- and inter-sector Edgeworth sympathy coefficients for the largest 1500 firms by market capitalization. Source: Authors' calculations using Thomson-Reuters 13F filings data on institutional ownership.

\subsection{Calibration}

The model is parsimonious enough that it can be calibrated with only a few parameters. In the U.S. economy and under our maintained assumption of proportional control, the weights that managers put on rivals' profits (i.e., the lambdas) have increased dramatically over the past decades. In the United States, for example, the 1500 largest firms (by market capitalization) nearly doubled their calibrated average intra-industry lambdas: from about 0.41 in 1985 to about 0.72 in 2017 (see Figure 2). We adjust these lambdas downward in our calibration to account for privately held firms (which we assume have no common ownership) representing 58.7\% of sales in the economy (Asker, Farre-Mensa, and Ljungqvist (2014)). The result is an increase, in average intra-industry lambdas, from 0.07 in 1985 to 0.124 in 2017 (and a similar increase for inter-industry lambdas). This increase in lambdas implies an increase in markups $(p / \mathrm{mc})$ from 1.49 to 1.61 over the period 1985-2017. That increase is smaller than the one estimated by De Loecker, Eeckhout, and Unger (2020) (from about 1.3 in the mid-1980s to 1.61 in 2016) and Hall (2018) (from 1.12 in 1988 to 1.38 in 2015), and it is smaller also than that implied by the calibration in Backus, Conlon, and Sinkinson (2019) based on a Bertrand competition model (which goes from about 1.21 in 1980 to about 1.56 in 2017). However, the increase we estimate is similar to the increase in markups measured by Nekarda and Ramey (2019): their markup index increases from about 90 to about 100 over 1985-2017-nearly an 11\% increase, which is roughly comparable to the $8.5 \%$ increase implied by our model. Also, the decline in the labor share implied by our model is similar to the decline measured by the U.S. Bureau of Labor Statistics (BLS; see Azar and Vives (2019a)).

The model has been extended in Azar and Vives (2019a) to include savings and capital, and shown able to reproduce macroeconomic trends such as the secular decline in the U.S. economy's labor share, and also approximate the decline in the capital share. The key to their approximation is using the evolution of effective (i.e., including the influence of common ownership) concentration in product and labor markets, thereby combining 
market power in product and labor markets with the evolution of common ownership. ${ }^{34}$ With this we do not claim that common ownership is the cause of the evolution of markups and markdowns and of the decline of labor and capital shares, but only that it has the potential to explain it.

The question arises as to what explains observed increases in the lambdas. BanalEstañol, Seldeslachts, and Vives (2018) examined 2004-2012 data for all publicly listed firms in the United States and documented that passive investors increased their holdings relative to active shareholders after the financial crisis. This need not lead necessarily to a higher degree of internalization of rivals' profits, since passive investors could (in principle) exert less control than active ones. However, passive shareholders are more diversified, and the shift toward passive investors does help explain (statistically) the increase in profit internalization. The authors also reported, for a cross-section of industries, a positive association between increases in the intra-industry lambda and increasing markups.

Atkeson and Burstein (2008) also calibrated a model of oligopoly in general equilibrium. Our calibrations are similar along some dimensions but differ along others. These authors calibrated higher product market power parameters ${ }^{35}$ but the two quantitative models differ substantially since we consider labor market power and common ownership whereas they do not. ${ }^{36}$ We have already mentioned that, although firms in their model are under full common ownership (by the representative household that owns all firms), those firms are still assumed to maximize profits. In our calibration, common ownership is only partial, but it is taken into account by the firms, reducing the effective number of firms to 3.2 in the product market and to 3.3 in the labor market in 2017 (the corresponding numbers for 1985 are 4.5 and 4.2). In addition, common ownership in our model implies a pro-competitive internalization of the inter-sectoral externality ${ }^{37}$ Overall, these differences imply that, in our model, the $(p-c) / p$ markup (including the labor and product market wedges) increases from $33 \%$ to $38 \%$ over the 1985-2017 period-as compared with the markup of $29 \%$ calculated by Atkeson and Burstein (2008) (even though their product market markup is much higher than our product market wedge).$^{38}$

\footnotetext{
${ }^{34} \mathrm{We}$ do not need to assume symmetric firms for the simulation since we can input the modified $\mathrm{HHI}$ for an asymmetric market structure. Indeed, an industry with a very uneven distribution of firms' market shares may have a high $H H I$ even with a large number of firms.

${ }^{35}$ For the inter-sectoral elasticity of substitution, we set $\theta=3$ based on estimates by Hobijn and Nechio (2015); in contrast, Atkeson and Burstein (2008) used a value of 1.01 "to keep sectoral expenditure shares roughly constant." Hence their calibration implies a much lower market-level elasticity of demand and thus the potential of far more market power in the product market. Since we assume that goods within a sector are homogeneous, our calibration of the intra-sector elasticity of substitution parameter is that it is infinite, while they calibrated it to 10 , which is a large number, but still implying some differentiation and therefore more product market power than in our model. Their assumptions imply an effective number of firms equal to 6.7 in the product market, whereas we calculate that number to decline from 6.1 to 4.6 over the period 1985-2017.

${ }^{36}$ Atkeson and Burstein (2008) assumed that firms are price takers in the labor market, whereas we assume that they have market power in the labor market. In particular, for the calibration we assume that labor markets are segmented by industry and that (based on estimates by Chetty et al. (2011)) the market-level elasticity of labor supply is 0.59 . Our labor market HHI increases from 1798 to 1965 over 1985-2017 (i.e., the effective number of firms declines from 5.6 to 5 ).

${ }^{37}$ The internalization of the externality does not disappear when the number of firms tends to infinity when firms are owned by a representative household owning the market portfolio, and therefore it still exists in a model with a continuum of firms.

${ }^{38}$ Finally, we remark that their model assumes constant returns in labor whereas we (a) assume decreasing returns and (b) calibrate the associated function parameter so that our calibrated model's labor share matches the BLS labor share in the year 1985.
} 


\section{COMPETITION POLICY}

In this section, we show how equilibrium outcomes in oligopolistic economies are suboptimal from a social welfare perspective before considering the potentially beneficial effects of competition policies. Our model is static and should therefore be interpreted as capturing only long-run phenomena. In this model, then, the low levels of output and employment are of a long-run nature and so could be affected by fiscal policy but not by monetary policy. ${ }^{39}$

Competition policy (broadly understood to encompass regulation) can influence aggregate outcomes by directly affecting product and labor market concentration-that is, by affecting the number of firms and also the extent of their ownership overlap. ${ }^{40} \mathrm{We}$ illustrate the analysis with the one-sector model Cobb-Douglas isoelastic specification. We explore in turn the social planner allocation (first best) and competition policy (second best); we then conclude with some remarks on the multi-sector model.

\subsection{Social Planner's Solution in the One-Sector Model}

Here we characterize-in the one-sector, Cobb-Douglas, additively separable, isoelastic model - the allocation that would be chosen by a benevolent social planner who maximizes a weighted sum of the utilities of all owner-consumers with weight $\kappa \in[0,1]$ and of all worker-consumers with weight $1-\kappa \cdot{ }^{41}$ We assume that the social planner can choose the allocation of labor and consumption as well as the number of firms (with access to a large number $\left.J^{\max }\right)$. Let $(C, L)$ be the consumption and labor supply of a representative worker, and let $C_{O}$ be the consumption of a representative owner; then the social planner's problem is constrained by $C+C_{O} \leq J A(L / J)^{\alpha}=A L^{\alpha}(1 / J)^{\alpha-1}$. This constraint will always hold, since otherwise it would be possible to increase welfare by increasing workers' consumption until the constraint binds. Hence the problem can be rewritten as

$$
\max _{C, L, J}(1-\kappa)\left(\frac{C^{1-\sigma}}{1-\sigma}-\chi \frac{L^{1+\xi}}{1+\xi}\right)+\kappa\left[A L^{\alpha} J^{1-\alpha}-C\right] .
$$

This problem can be solved in two steps. First, we choose the welfare-maximizing $C$ and $L$ conditional on the number $J$ of firms that are used (symmetrically) in production. Second, we maximize over $J$ to obtain the optimal number of firms from the social planner's perspective.

The first-order conditions (which are sufficient under non-increasing returns to scale) for the first maximization problem ensure that, in an interior solution, (i) the marginal utility $C^{-\sigma}$ of workers' consumption is equal to $\kappa /(1-\kappa)$ multiplied by the owners' marginal utility of consumption (which is constant and equals 1) and (ii) $C^{-\sigma}$ is equal also to the marginal disutility from working divided by the marginal product of labor:

\footnotetext{
${ }^{39}$ The effects of government employment policies are examined in Azar and Vives (2019b).

${ }^{40} \mathrm{We}$ do not consider here conduct regulation to limit markdowns and markups under a free entry constraint (see, e.g., Vives (1999), Section 6). Note, however, that conduct regulation is approximated here by controlling common ownership because of its direct link with margins.

${ }^{41}$ One can interpret $\kappa$ as determining the welfare standard used by society. Thus $\kappa=0$ represents the case of a "worker-consumer welfare standard" in which owners' utilities are assigned zero weight; this case is analogous-in our general equilibrium oligopoly model - to that of the usual partial equilibrium consumer welfare standard. The case $\kappa=1 / 2$ corresponds to a "total welfare standard" in which all agents' utilities are equally weighted.
} 
$\chi L^{\xi} /\left(A \alpha(L / J)^{\alpha-1}\right){ }^{42}$ This condition cannot hold in an oligopsonistic equilibrium because the markdown of wages relative to the marginal product of labor is positive, which introduces a wedge between the marginal product of labor and the real wage.

How many firms will the social planner choose to involve in the production process? If there are decreasing returns to scale, then social benefits are increasing in $J$ and so the optimal choice is $J^{\max }$. With constant returns to scale, the number of firms in operation is irrelevant. Under increasing returns to scale, the social planner would choose to produce using only one firm; however, the planner would still set-contra the monopsonistic outcome - the marginal product of labor equal to the marginal rate of substitution between consumption and labor. ${ }^{43}$ Thus, from the viewpoint of a social planner, there is no Williamson trade-off because the planner can set the "shadow" markdown to zero and still benefit fully from the economies of scale due to producing with only one firm. Next, we address the second-best allocation, under which the planner can affect the oligopoly equilibrium only by controlling the variables $J$ and $\phi$.

\subsection{Competition Policy}

The models developed so far illustrate how the level of competition in the economy has macroeconomic consequences, from which it seems reasonable to conclude that competition policy may stimulate the economy by boosting output and inducing a more egalitarian distribution of income. We showed that if returns to scale are non-increasing, then employment, output, real wages, and the labor share all decrease under higher market concentration and more common ownership.

In the one-sector case, the equilibrium modified HHI $(H)$ is the same for the product and labor markets and is proportional to the markdown of wages relative to the marginal product of labor in the economy. In the multi-sector case, the markdown is a function of both the within-industry and the economy-wide modified HHIs, of which the latter is most relevant for the labor market. (In practice, labor markets are segmented and so the labor market modified HHI would differ from the economy-wide one; however, the insight would be similar.)

\subsubsection{Worker-Consumer Welfare}

We can view the competition policy in our model as setting a policy environment that affects - in a symmetric equilibrium - the number of firms per industry and/or the extent of common ownership. We start by showing that $1-\phi$ and $J$ are complements as policy tools. Then common ownership mitigates the effect of "traditional" competition policy on employment because increasing the number of firms has less of an effect on concentration when firms' shareholders are more similar.

PROPOSITION 6: Let $\alpha<1+1 / \eta$ and let $L^{*}$ be a symmetric equilibrium. Then reducing common ownership (increasing $1-\phi$ ) and reducing concentration (increasing $J$ ) are complements as policy tools for increasing equilibrium employment.

\footnotetext{
${ }^{42}$ However, it is possible-for sufficiently low values of $\kappa$-for there to be a corner solution such that all the output is assigned to the workers and the consumption of the owners is zero; that is, $C=A L^{\alpha}$ and $C_{O}=0$.

${ }^{43}$ With increasing returns to scale, and $\alpha<1+\xi$, the objective of the social planner is convex in $L$ below a threshold, and concave in $L$ above that threshold. This guarantees that the optimal $L$ is strictly positive (however, just like in the non-increasing returns case, there can be a corner solution for the consumption of the workers and the owners, that is, $C=A L^{\alpha}$ and $C_{O}=0$ ). If $\alpha>1+\xi$, in some cases there could be a corner solution with $L=0$.
} 
The proposition follows because it can be shown that

$$
\operatorname{sgn}\left\{\frac{\partial^{2} \log L^{*}}{\partial(1-\phi) \partial J}\right\}=\operatorname{sgn}\left\{-(J-1)(1-\lambda) \frac{\partial \lambda}{\partial(1-\phi)}\right\}>0
$$

for $J>1, \eta<\infty$, and $\frac{\partial \lambda}{\partial(1-\phi)}<0$. We remark that this proposition holds under decreasing returns and also in our increasing returns example (see Appendix A) with $\eta \leq 1$ and $\alpha \in(1,2)$.

Under either constant or decreasing returns to scale, it is always welfare-increasing for worker-consumers if the planner's policy reduces diversification (common ownership) and increases the number of firms-although the latter claim need not apply under increasing returns. Under non-increasing returns, the result follows because $L^{*}$ increases with both $1-\phi$ and $J$, equilibrium real wages increase with employment, and workerconsumer utility increases with real wages. Under increasing returns, however, there is a trade-off between market power and efficiency; in this scenario, the optimal number of firms (from the perspective of worker-consumer welfare) is limited. ${ }^{44}$ In short: if returns to scale are increasing, then a decrease in the equilibrium markdown does not always translate into an increase in worker-consumer welfare. When returns are non-increasing, however, competition policy can lead to equilibria that are arbitrarily close to the social planner's as $J^{\text {max }}$ becomes large. This is because the markdown then becomes arbitrarily close to zero.

Entry. Until now, we have assumed that the number of firms is fixed. We could consider an extension of the model whereby a large number of groups of potential owners can create new firms by paying a fixed cost. Once a new firm is created, its shares can be traded on the stock market. If we assume that the group creating the firm must retain a fraction $1-\phi$ of the firm's shares yet can also exchange up to $\phi$ of their shares for shares in the index, then we can easily re-create our model as a post-entry stage during which entry decisions depend on the entrant's expected profitability. In this world, common ownership will tend to magnify the excess entry results that hold in a Cournot market (see, e.g., Vives (1999)) although, according to some preliminary results, it will lead to decreased output and depressed wages as $\phi$ increases, only punctuated by upward jumps when a new firm enters.

\subsubsection{Positive Weight on Owner-Consumer Welfare}

The polar case of $\kappa=1$, when the social planner maximizes the utility of the ownerconsumers only, can easily be seen to imply-if we assume $\eta \leq 1$ - that setting $\phi=1$ will result in a completely concentrated economy in terms of the modified HHI, while choosing the number of firms to produce as efficiently as possible, which implies setting $J=J^{\max }$ in the case of decreasing returns, $J=1$ in the case of increasing returns, and any $J \in\left\{1, \ldots, J^{\max }\right\}$ in the case of constant returns. For intermediate values of $\kappa$, there is no simple analytic solution to the problem of choosing a competition policy that maximizes social welfare. Yet we do know that, as $\kappa$ increases, owner-consumer welfare increases while worker-consumer welfare declines; the implication is that equilibrium employment and wages are both lower when $\kappa$ is higher. Azar and Vives (2018) simulated the optimal policy as a function of $\kappa$; they found that, with decreasing returns to scale, $\phi$ weakly

\footnotetext{
${ }^{44}$ One can easily check that, for $\alpha \in(1,2)$ and $\eta \leq 1$, the total employment level $L^{*}$ increases with $1-\phi$ and peaks for $J$ (when considered as a continuous variable) at $\eta^{-1}(2-\alpha) /(\alpha-1)$. If $J>\eta^{-1}(2-\alpha) /(\alpha-1)$, then $\alpha-1>(\eta J)^{-1}\left(1+(\eta J)^{-1}\right)^{-1}$ and the equilibrium would be unstable (see Appendix A).
} 
increases to 1 as $\kappa$ tends to 1 , and owner-consumer's welfare weakly increases, and employment and worker welfare weakly decrease, with $\kappa^{45}$

\subsubsection{Heterogeneous Firms}

Suppose firms have heterogeneous CRS technologies. Then, by Proposition 2(b), it is optimal to set $\phi=0$ if the aim is to maximize employment. Now suppose that the least efficient firm exits the market; then average productivity of the remaining firms will increase but total output and hired labor may decline. This is what happens with a constant elasticity of labor supply. ${ }^{46}$ Although removing the least productive firm reduces worker welfare, total welfare (including both worker-consumer and owner-consumer welfare) can either increase or decrease.

As an example, consider an economy with two firms and parameters $\sigma=1 / 3, \xi=1 / 3$, $\chi=1$, and $A_{1}=1$. Suppose the common ownership parameter is $\phi=3 / 4$ (yielding $\lambda=$ 0.5172 ) and that the social welfare function parameter $\kappa$ is $1 / 2$. In that case, if $A_{2}=0.8$ (i.e., if firm 2 is $80 \%$ as productive as firm 1), then removing firm 2 increases total welfare; whereas if $A_{2}=0.9$, then removing firm 2 reduces total welfare. If $\phi=1 / 8$ (such that $\lambda=0.1064$ ), then removing firm 2 increases total welfare if $A_{2}=0.6$ but reduces it if $A_{2}=0.9$. Dropping one firm will be the outcome of a merger to monopoly, which owners will always favor despite the possibility of its reducing total welfare.

\subsubsection{Competition Policy With Multiple Sectors}

In the one-sector case with the worker-consumer welfare standard $(\kappa=0)$, it is always efficient to force completely separate ownership of firms, regardless of how many firms there are, because there are no efficiencies associated with common ownership. In the multi-sector case, however, common ownership is associated with internalization of demand effects in other sectors; this means that-depending on the elasticity of substitution, the elasticity of labor supply, and the number of firms per industry-worker-consumers could be better-off under complete indexation of the economy. In any case, if maximizing employment is the goal, then it is better to set the intra-industry index fund ownership to zero (i.e., $\widetilde{\phi}=0$ ), and, if returns to scale are decreasing, produce with the maximum number $J^{\text {max }}$ of firms. Along these lines, what follows can be viewed as a corollary of our previous results.

In short, with $N$ sectors and non-increasing returns to scale, employment, real wages, and the welfare of worker-consumers are maximized when $J=J^{\max }, \tilde{\phi}=0$, and when $\phi=0$ (resp., $\phi=1)$ if $\theta\left(J^{\max }-1 / N\right)>(1+\eta)(1-1 / N)$ (resp., if inequality is reversed). So if the product market wedge effect dominates the labor market wedge effect (i.e., low $\theta$ and high $\eta$ ), then allowing full economy-wide common ownership increases equilibrium employment. Conversely, if the labor market wedge effect dominates the product market wedge effect, then the optimal policy, as in the one-sector case, is no common ownership.

For large economies, the following analogous result holds. There exists an $\hat{N}$ such that, for economies with $N>\hat{N}$, maximizing employment requires that the planner: (i) set $\widetilde{\phi}=0$ and $J=J^{\text {max }}$; and (ii) set $\phi=0$ if $\theta J-1>\eta$ but $\phi=1$ if $\theta J-1<\eta .^{47}$

\footnotetext{
${ }^{45}$ With increasing returns to scale, it is easy to generate examples where it is optimal-even from the workerconsumers' standpoint, $\kappa=0$-if some market power is allowed so as to exploit economies of scale. Typically, the number of firms declines as $\kappa$ increases.

${ }^{46}$ Proof available on request.

${ }^{47}$ Even under Neary's (2003b) assumption of no common ownership, competition policy has an effect when firms across all sectors employ the same CRS technology. This result follows because, in our model, the supply
} 


\section{CONCLUSION}

We have provided a tractable model of oligopoly in general equilibrium that accommodates the influence of ownership structure. By assuming that managers maximize a weighted sum of utilities of shareholders in a firm, we identify a numéraire-free CournotWalras equilibrium and characterize it. In our model, firms' employment decisions affect prices in both product and factor markets. We find that a higher effective market concentration, which accounts for portfolio diversification and common ownership, increases markups and reduces both real wages and employment. Furthermore, when firms have heterogeneous CRS technologies, an increase in common ownership tilts the scales in favor of more efficient (superstar) firms and raises market concentration. When there are multiple industries, common ownership can have a positive or negative effect on the equilibrium markup: the sign of the effect depends on the relative magnitudes of the elasticities of product substitution and of labor supply. We find also that the monopolistically competitive limit (as in, e.g., Dixit and Stiglitz (1977)) or the oligopolistic one (Neary (2003a, 2003b), Atkeson and Burstein (2008)) may or may not be attained as the number of sectors in the economy grows large depending on the parallel evolution of diversification.

Competition policy can increase employment and improve welfare. In the one-sector economy, we find that controlling common ownership and reducing concentration are complements in terms of fostering employment. With multiple sectors, to foster employment, traditional competition policy on market concentration is adequate. However, common ownership can have a positive or negative effect on employment. Although its effect is negative in the intra-industry case, it could be positive in the case of economy-wide common ownership.

Some caveats to our results follow from considering vertical relations between firms, and possibly different patterns of consumption between owners and workers. For example, vertical relations imply that products of one sector may serve as inputs for another sector. Then common ownership may lead to partial internalization of double marginalization and decrease markups. ${ }^{48}$

In general, our results indicate a need to go beyond traditional partial equilibrium analyses of competition policy, where consumer surplus is king. However, traditional competition policy (e.g., lowering market concentration) remains a valid approach-as is limiting intra-industry ownership. That said, policy regarding economy-wide common ownership requires a more nuanced approach.

The models presented here are extremely stylized. We do not consider asymmetries in ownership structure across firms. Because the ownership structure is exogenous, with a separation between owners and workers, we consider neither the benefits of diversification in an uncertain world nor the effects of unions' market power on the labor market. The models considered are static; dynamic versions incorporating uncertainty and adjustment costs may shed light on how oligopoly affects such issues as monetary policy transmission. In other words, there is ample room in future research for extensions and generalizations of our approach.

of labor is elastic (and so changes in the real wage affect both employment and output) and there are two types of agents. If our model included only worker-owner-consumers, then the representative agent would always choose the optimal level of employment.

${ }^{48} \mathrm{Azar}$ (2012) found that common ownership links across industries are associated with lower markups. 


\section{APPENDIX A: INCREASING RETURNS TO SCALE}

If $\alpha>1$, then neither the inequality $-F^{\prime \prime}+(1-\lambda) \omega^{\prime}>0$ nor the payoff global concavity condition need hold. We characterize the situation where $\alpha \in(1,2)$ and $\eta \leq 1$. Then, with respect to $L_{j}$, firm $j$ 's objective function has a convex region below a certain threshold and a concave region above that threshold. Hence we conclude that there are no more than two candidate maxima for $L_{j}$, when given the other firms' decisions, at a symmetric equilibrium: $L_{j}=0$; and the critical point in the concave region (if there is any). We identify (after some work) the following necessary and sufficient condition for the candidate interior solution to be a symmetric equilibrium: $\alpha \leq(1+H / \eta)\left\{1+\lambda(J-1)\left[1-(1-1 / J)^{1 / \eta}\right]\right\}^{-1} \cdot{ }^{49}$ For small $\lambda$, if an equilibrium exists, then it is stable. Here $L^{*}$ is decreasing in $\phi$, but it may either increase or decrease with $J$ :

$$
\frac{\partial \log L^{*}}{\partial J}=\frac{1}{1-\alpha+1 / \eta} \frac{1}{J}(\underbrace{(1-\lambda) \frac{H / \eta}{1+H / \eta}}_{\text {Markdown effect }}-\underbrace{(\alpha-1)}_{\text {Economies of scale effect }}) .
$$

Increasing the number of firms has two effects on a symmetric equilibrium with increasing returns to scale: a positive effect from fewer markdowns, and a negative effect from reduced economies of scale. Thus, a merger between two firms (decreasing $J$ ) would involve a so-called Williamson trade-off between higher market power and the efficiencies stemming from a larger scale of production. In our example, a merger would increase equilibrium employment if $\alpha$ were high enough to dominate the markdown effect.

A higher MHHI (the $H$ in our formulation) makes it more difficult for the scale effect to dominate. Yet for a given $H$, a higher internalization $\lambda$ makes it easier for that effect to dominate because if $\lambda$ is high enough, then firms will act jointly irrespective of their total number $J$. In fact, if they act fully as one firm $(\lambda=1)$, then the condition is always fulfilled. Thus, reducing $J$ improves scale but does not affect the markdown because it is already at the monopoly level. It is easy to generate examples where, under increasing returns, there are multiple equilibria and some firms do not produce.

\section{APPENDIX B: PROOFS}

ProOf of Proposition 1: The objective of firm j's manager is to maximize

$$
\zeta(\mathbf{L})=F\left(L_{j}\right)-\omega(L) L_{j}+\lambda \sum_{k \neq j}\left[F\left(L_{k}\right)-\omega(L) L_{k}\right] .
$$

The first derivative $\partial \zeta / \partial L_{j}$ is given by $F^{\prime}-\omega-\omega^{\prime}\left(L_{j}+\lambda \sum_{k \neq j} L_{k}\right)$, so the best response of firm $j$ depends only on $\sum_{k \neq j} L_{k}$. The cross-derivative $\partial^{2} \zeta / \partial L_{j} \partial L_{m}$ equals

$$
-\omega^{\prime}(1+\lambda)-\left(L_{j}+\lambda \sum_{k \neq j} L_{k}\right) \omega^{\prime \prime}=-\omega^{\prime}(1+\lambda)-\left(s_{j}+\lambda s_{-j}\right) \omega^{\prime \prime} L,
$$

where $s_{j} \equiv L_{j} / L$ and $s_{-j} \equiv \sum_{k \neq j} L_{k} / L$. If $E_{\omega^{\prime}} \equiv-\omega^{\prime \prime} L / \omega^{\prime}<1$, then the cross-derivative is negative because $s_{j}+\lambda s_{-j} \leq 1$ and

$$
-(1+\lambda)-\left(s_{j}+\lambda s_{-j}\right) \omega^{\prime \prime} L / \omega^{\prime}<-(1+\lambda)+\left(s_{j}+\lambda s_{-j}\right)<-\lambda .
$$

\footnotetext{
${ }^{49}$ The symmetric equilibrium is locally stable under continuous adjustment provided that $\alpha-1 \leq(1-$ $\lambda)(J \eta)^{-1}(1+H / \eta)^{-1}$.
} 
In this case, Theorem 2.7 of Vives (1999) guarantees the existence of an equilibrium. The second derivative $\partial^{2} \zeta /\left(\partial L_{j}\right)^{2}$ equals $F^{\prime \prime}-2 \omega^{\prime}-\left(L_{j}+\lambda \sum_{k \neq j} L_{k}\right) \omega^{\prime \prime}$, and it is negative provided that $F^{\prime \prime} \leq 0$ also. Let $L_{-j} \equiv \sum_{k \neq j} L_{k}$ and let $R\left(L_{-j}\right)$ denote the best response of firm $j$. Then

$$
R^{\prime}=-\frac{-\left((1+\lambda) \omega^{\prime}+\left(L_{j}+\lambda \sum_{k \neq j} L_{k}\right) \omega^{\prime \prime}\right)}{F^{\prime \prime}-\left(2 \omega^{\prime}+\left(L_{j}+\lambda \sum_{k \neq j} L_{k}\right) \omega^{\prime \prime}\right)} .
$$

If the second-order condition holds, then $R^{\prime}>-1$ whenever $-F^{\prime \prime}+(1-\lambda) \omega^{\prime}>0$ and, indeed, whenever $F^{\prime \prime} \leq 0$ (except if $F^{\prime}=0$ and $\lambda=1$ ). When $R^{\prime}>-1$, Theorem 2.8 in Vives (1999) guarantees that the equilibrium is unique.

Since $E_{\omega^{\prime}}<1$ and $F^{\prime \prime} \leq 0$, it follows that $\partial^{2} \zeta /\left(\partial L_{j}\right)^{2}<0$ and $\partial^{2} \zeta / \partial L_{j} \partial L_{k}<0$ for $k \neq j$. Then the equilibrium is locally stable under continuous adjustment dynamics if $\partial^{2} \zeta /\left(\partial L_{j}\right)^{2}<\partial^{2} \zeta / \partial L_{j} \partial L_{k}$ (see, e.g., Dixit (1986)). This inequality holds provided that $F^{\prime \prime}<(1-\lambda) \omega^{\prime}$, which is true if $F^{\prime \prime}<0$ or if $F^{\prime \prime} \leq 0$ and $\lambda<1$.

(a) From the first-order condition we have that, in a symmetric equilibrium, $s_{j}=1 / J$ for every $j$ and

$$
\frac{F^{\prime}(L / J)-\omega(L)}{\omega(L)}=\frac{\omega^{\prime}(L) L}{\omega(L)}\left(\frac{1}{J}+\lambda \frac{J-1}{J}\right) .
$$

The derivative of the markdown with respect to $\lambda$ is given by

$$
\frac{\partial \mu}{\partial \lambda}=\frac{F^{\prime \prime}(L / J) \omega(L) \frac{1}{J} \frac{\partial L}{\partial \lambda}-F^{\prime}(L / J) \omega^{\prime}(L) \frac{\partial L}{\partial \lambda}}{(\omega(L))^{2}} .
$$

The term $F^{\prime \prime}(L / J) \omega(L) \frac{1}{J} \frac{\partial L}{\partial \lambda}$ is nonnegative if $\frac{\partial L}{\partial \lambda}<0$, and $-F^{\prime}(L / J) \omega^{\prime}(L) \frac{\partial L}{\partial \lambda}$ is positive if $\frac{\partial L}{\partial \lambda}<0$. We show in part (b) of this proof that $\frac{\partial L}{\partial \lambda}<0$.

(b) The symmetric equilibrium is given by the fixed point of $L_{-j} /(J-1)=R\left(L_{-j}\right)$. Total employment is $L=L_{-j}+R\left(L_{-j}\right)$, which is increasing in $L_{-j}$ because $R^{\prime}>-1$. Furthermore, $R$ is decreasing in $\lambda$ because the objective function's first derivative is decreasing in $\lambda$. This implies that $L_{-j}$-and hence also that $L$ and $\omega(L)$ are decreasing in $\lambda$ (and in $\phi$ ). We have in addition that $L_{-j}$ is increasing in $J$ since $R^{\prime}<0$ and since $R$ is itself increasing in $J$ (i.e., because $R$ is decreasing in $\lambda$ and $\lambda$ is decreasing in $J$ ). Therefore, in equilibrium, $L$ and $\omega(L)$ increase with $J$.

(c) The labor share is $\frac{\omega(L) L}{J F(L / J)}$, and the derivative with respect to total employment $L$ is

$$
\frac{\omega^{\prime}(L) L+\omega(L)\left[F(L / J)-(L / J) F^{\prime}(L / J)\right]}{J(F(L / J))^{2}}>0
$$

given that returns to scale are non-increasing, $F(L / J)-(L / J) F^{\prime}(L / J) \geq 0 .{ }^{50}$ Since employment is decreasing in $\phi$, that implies the labor share is decreasing in $\phi$ as well. Q.E.D.

The following lemma will be useful in the proof of Proposition 2.

\footnotetext{
${ }^{50}$ If $F(x)$ is increasing and concave for $x \geq 0$ with $F(0) \geq 0$, then $F(x) / x \geq F^{\prime}(x)$.
} 
LEMMA 1: Suppose $E_{\omega^{\prime}}<1$ and that firms have (possibly heterogeneous) CRS production functions. Then, in equilibrium, $\frac{\partial \eta}{\partial \lambda}+1>0$.

PRoOF: We calculate the derivative $\frac{\partial \eta}{\partial \lambda}$ in two parts: as the product of $\frac{\partial \eta}{\partial \log L}$ and $\frac{\partial \log L}{\partial \lambda}$. We find that

$$
\frac{\partial \eta}{\partial \log L}=1-\eta\left(1-E_{\omega^{\prime}}\right)<1
$$

where the last inequality holds because both $\eta$ and $\left(1-E_{\omega^{\prime}}\right)$ are positive.

To obtain an expression for $\frac{\partial \log L}{\partial \lambda}$, we take a simple average of the first-order conditions of the firms and then differentiate with respect to $\lambda$ :

$$
\frac{\partial \log L}{\partial \lambda}=-\frac{1-1 / J}{1+[1 / J+\lambda(1-1 / J)]\left(1-E_{\omega^{\prime}}\right)}<0
$$

the absolute value of this expression is less than 1 . This fact, when combined with the inequality $\frac{\partial \eta}{\partial \log L}<1$, implies that $\frac{\partial \eta}{\partial \lambda}>-1$; therefore, $\frac{\partial \eta}{\partial \lambda}+1>0$.

Q.E.D.

ProOF OF PROPOSITION 2: As in the proof of Proposition 1, our analysis establishes the existence of a unique equilibrium when $\lambda<1$. This claim follows directly because the slope of firm $j$ 's best response is given by the same expression as before just letting $F^{\prime \prime}=0$.

(a) From the first-order condition for firm $j$, we obtain that its markdown is given by

$$
\frac{A_{j}-\omega}{\omega}=\frac{s_{j}+\lambda\left(1-s_{j}\right)}{\eta(L)} .
$$

Taking an average weighted by market shares now yields Proposition 2's expression for the weighted average markdown:

$$
\sum_{j=1}^{J} s_{j} \frac{A_{j}-\omega}{\omega}=\frac{\mathrm{HHI}(1-\lambda)+\lambda}{\eta(L)} .
$$

Solving for $s_{j}$ yields

$$
s_{j}=\frac{1}{J} \frac{A_{j}}{\bar{A}}+\left(\frac{A_{j}}{\bar{A}}-1\right) \frac{\eta+\lambda}{1-\lambda},
$$

where $\bar{A} \equiv\left(\sum_{j=1}^{J} A_{j}\right) / J$. We show that the HHI increases with $\phi$ whenever there is variation in firms' productivities, which is equivalent to showing that the HHI increases with $\lambda$. We find that

$$
\begin{aligned}
\frac{\partial \mathrm{HHI}}{\partial \lambda} & =\sum_{j=1}^{J} 2 s_{j} \frac{\partial s_{j}}{\partial \lambda} \\
& =2 \sum_{j=1}^{J}\left\{s_{j}\left(\frac{A_{j}}{\bar{A}}-1\right)\left[\frac{\left(1+\frac{\partial \eta}{\partial \lambda}\right)(1-\lambda)+\eta+\lambda}{(1-\lambda)^{2}}\right]\right\}
\end{aligned}
$$




$$
=2\left[\frac{\left(1+\frac{\partial \eta}{\partial \lambda}\right)(1-\lambda)+\eta+\lambda}{(1-\lambda)^{2}}\right]\left(\frac{\sum_{j=1}^{J} s_{j} A_{j}}{\bar{A}}-1\right) .
$$

Note that the last factor is positive, because the weighted average of the productivities is larger than the unweighted average:

$$
\sum_{j=1}^{J}\left[\frac{1}{J} \frac{A_{j}}{\bar{A}}+\left(\frac{A_{j}}{\bar{A}}-1\right) \frac{\eta+\lambda}{1-\lambda}\right] A_{j}=\bar{A}\left[1+\left(1+\frac{(\eta+\lambda) J}{1-\lambda}\right) \frac{\sigma_{A}^{2}}{\bar{A}^{2}}\right]>\bar{A} ;
$$

here $\sigma_{A}^{2}=\left(\sum_{j=1}^{J}\left(A_{j}-\bar{A}\right)^{2}\right) / J$ is the variance of firms' productivities.

The first factor in the last line of (B.1) is positive as long as (a) there is dispersion in the productivities and (b) $1+\frac{\partial \eta}{\partial \lambda}>0$, which Lemma 1 establishes while assuming that $E_{\omega^{\prime}}<1$. Therefore, an increase in $\lambda$ increases the Herfindahl-Hirschman index.

The derivative of the modified $\mathrm{HHI}$ with respect to $\lambda$ is

$$
\frac{\partial H}{\partial \lambda}=\frac{\partial(\mathrm{HHI}(1-\lambda)+\lambda)}{\partial \lambda}=\frac{\partial \mathrm{HHI}}{\lambda}(1-\lambda)-\mathrm{HHI}+1>0 .
$$

To show that $\bar{\mu}$ is increasing in $\lambda$, we rewrite it as

$$
\bar{\mu}=\frac{\bar{A}\left[1+\left(1+\frac{(\eta+\lambda) J}{1-\lambda}\right) \frac{\sigma_{A}^{2}}{\bar{A}^{2}}\right]}{\omega}-1
$$

and find that

$$
\frac{\partial \bar{\mu}}{\partial \lambda}=\frac{J \frac{\sigma_{A}^{2}}{\bar{A}} \frac{(\partial \eta / \partial \lambda+1)(1-\lambda)+(\eta+\lambda)}{(1-\lambda)^{2}} \omega-\bar{\mu} \omega \omega^{\prime} \frac{\partial L}{\partial \lambda}}{\omega^{2}}>0,
$$

since $1+\frac{\partial \eta}{\partial \lambda}>0$ and $\frac{\partial L}{\partial \lambda}<0$.

(b) That $L^{*}$ decreases with $\lambda$ was shown in part (a). Because labor supply is increasing, $\omega\left(L^{*}\right)$ also decreases with $\lambda$.

(c) The labor share in this case is

$$
\frac{\omega(L) L}{\sum_{j=1}^{J} A_{j} L_{j}}=\frac{\omega(L)}{\sum_{j=1}^{J} s_{j} A_{j}}=\frac{1}{1+\bar{\mu}} .
$$

As shown in part (a), $\bar{\mu}$ is increasing in $\lambda$ and so the labor share must be decreasing in $\lambda$.

(d) We showed in part (a) that HHI increases with $\lambda$ when technologies differ. Now we show that the minimal productivity for a firm to be viable is increasing in $\lambda$. Assume, without loss of generality, that the firms are sorted by productivity: $A_{1} \geq A_{2} \geq \cdots \geq A_{J}$. From the firms' first-order conditions, it follows that the condition for all firms to produce 
a positive amount in equilibrium is that

$$
s_{J}=\frac{1}{J} \frac{A_{J}}{\bar{A}}+\left(\frac{A_{J}}{\bar{A}}-1\right) \frac{\eta(L)+\lambda}{1-\lambda}>0 .
$$

The implication is that, in order for the least productive firm to produce in equilibrium, its productivity relative to average productivity $\left(A_{J} / \bar{A}\right)$ must exceed the threshold $\frac{(\eta+\lambda) /(1-\lambda)}{(\eta+\lambda) /(1-\lambda)+1 / J}$. This threshold is increasing in $\lambda$ (assuming that $E_{\omega^{\prime}}<1$ ). To see that the threshold is increasing in $\lambda$, note that its derivative with respect to $\lambda$ is $\frac{(\eta+\lambda)+(1-\lambda)(\partial \eta / \partial \lambda+1)}{J[(\eta+\lambda) /(1-\lambda)+1 / J]^{2}(1-\lambda)^{2}}$, which is positive when $E_{\omega^{\prime}}<1$ because (by Lemma 1$) \frac{\partial \eta}{\partial \lambda}+1>0$. More generally, a necessary condition for the $j$ th least productive firm to produce a positive amount in equilibrium is

$$
\frac{A_{j}}{\bar{A}_{j}}>\frac{(\eta+\lambda) /(1-\lambda)}{(\eta+\lambda) /(1-\lambda)+1 / j}
$$

where $\bar{A}_{j}=\sum_{k=1}^{j} A_{k} / j$ is the average of the productivities of the most efficient firms $1, \ldots, j$. Therefore, if it is not profitable for firm $j$ to produce in equilibrium with $\lambda$, then neither is it profitable to produce in equilibrium with $\lambda^{\prime}>\lambda$.

Q.E.D.

The following lemma establishes the comparative statics properties of $\lambda_{\text {intra }}$ and $\lambda_{\text {inter }}$ with respect to the common ownership parameters $\phi, \widetilde{\phi}, N$, and $J$.

LEMMA 2: The terms $\lambda_{\text {intra }}$ and $\lambda_{\text {inter }}$ are: (i) increasing in $\phi$ and $\widetilde{\phi}$; (ii) for $\phi>0$ and $\phi+\widetilde{\phi}<1$, and for $\phi \in(0,1)$, decreasing in $N$ (but are otherwise constant as functions of $N)$; (iii) decreasing in $J$ when $\phi+\widetilde{\phi}<1$ but constant as functions of $J$ when $\phi+\widetilde{\phi}=1$; and (iv) always in $[0,1]$.

PROOF: Using the expressions for $\lambda_{\text {intra }}$ and $\lambda_{\text {inter }}$ from Section 4.1, we proceed by establishing these four claims in turn.

(i) The sign of the derivative of $\lambda_{\text {intra }}$ with respect to $\phi$ is given by

$$
\operatorname{sgn}\left\{\frac{\partial \lambda_{\text {intra }}}{\partial \phi}\right\}=\operatorname{sgn}\left\{(1-\phi)(1-\phi-\widetilde{\phi})^{2}+(1-\phi-\widetilde{\phi})[(2-\phi) \phi+(1-\phi) \widetilde{\phi} N]\right\} \text {. }
$$

In this expression: the first term is always nonnegative (and positive if $1-\phi-\widetilde{\phi}>0$ ); the second term is always nonnegative (and positive if $1-\phi-\widetilde{\phi}>0$, and either $\phi>0$ or $\widetilde{\phi}>0$ ). Hence the derivative is positive in the interior of $\phi$ 's domain, from which it follows that $\lambda_{\text {intra }}$ increases with $\phi$.

The sign of the derivative of $\lambda_{\text {inter }}$ with respect to $\phi$ is given by

$$
\begin{aligned}
& \operatorname{sgn}\left\{\frac{\partial \lambda_{\text {inter }}}{\partial \phi}\right\} \\
& \quad=\operatorname{sgn}\left\{\begin{array}{c}
\left.(2-\phi) \phi[(1-\phi-\widetilde{\phi}) J+\widetilde{\phi}]+2(1-\phi) J\left[(1-\phi)^{2}-[2(1-\phi)-\tilde{\phi}] \tilde{\phi}\right]\right\} ; \\
+[2(1-\phi)-\tilde{\phi}] \tilde{\phi}
\end{array}\right.
\end{aligned}
$$

here the first term is always nonnegative and positive when $0<\phi<1$, the middle term is always nonnegative and positive when $1-\phi-\widetilde{\phi}>0$, and the last term is always nonnegative and positive when $\widetilde{\phi}>0$. Thus the derivative is positive in the interior of $\phi$ 's domain, so $\lambda_{\text {inter }}$ is increasing in $\phi$. 
We have that

$$
\begin{aligned}
\operatorname{sgn} & \left\{\frac{\partial \lambda_{\text {intra }}}{\partial \widetilde{\phi}}\right\} \\
= & \operatorname{sgn}\left\{\begin{array}{r}
(1-\phi-\widetilde{\phi}) 2 N\left[(1-\phi)^{2} J N+(2-\phi) \phi-[2(1-\phi)-\widetilde{\phi}] \widetilde{\phi} N(J-1)\right. \\
+(J-1)[(2-\phi) \phi+[2(1-\phi)-\widetilde{\phi}] \widetilde{\phi} N]]
\end{array}\right\} \\
= & \operatorname{sgn}\left\{(1-\phi-\widetilde{\phi}) 2 J N\left[(1-\phi)^{2} N+(2-\phi) \phi\right]\right\} ;
\end{aligned}
$$

therefore, the derivative is positive in the interior of $\widetilde{\phi}$ 's domain and so $\lambda_{\text {intra }}$ increases with $\widetilde{\phi}$.

Now

$$
\operatorname{sgn}\left\{\frac{\partial \lambda_{\text {inter }}}{\partial \widetilde{\phi}}\right\}=\operatorname{sgn}\{(1-\phi-\widetilde{\phi}) 2 N(J-1)[(2-\phi) \phi+[2(1-\phi)-\widetilde{\phi}] \widetilde{\phi} N]\}
$$

because $(2-\phi) \phi \geq 0$ (with inequality if $\phi>0$ ). Also, $[2(1-\phi)-\widetilde{\phi}] \widetilde{\phi} \geq 0$ (with inequality if $\widetilde{\phi}>0$ ) and the derivative is positive in the interior of $\widetilde{\phi}$ 's domain. We therefore conclude that $\lambda_{\text {inter }}$ is increasing in $\widetilde{\phi}$.

(ii) The sign of the derivative of $\lambda_{\text {intra }}$ with respect to $N$ is given by

$$
\begin{aligned}
\operatorname{sgn} & \left\{\frac{\partial \lambda_{\text {intra }}}{\partial N}\right\} \\
& =\operatorname{sgn}\left\{[2(1-\phi)-\widetilde{\phi}] \widetilde{\phi}(2-\phi) \phi-(2-\phi) \phi\left[(1-\phi)^{2} J-[2(1-\phi)-\widetilde{\phi}] \widetilde{\phi}(J-1)\right]\right\} \\
& =-\operatorname{sgn}\left\{(2-\phi) \phi\left[(1-\phi)^{2} J-[2(1-\phi)-\widetilde{\phi}] \widetilde{\phi} J\right]\right\} \\
& =-\operatorname{sgn}\left\{(2-\phi) \phi\left[(1-\phi)^{2}-[2(1-\phi)-\widetilde{\phi}] \widetilde{\phi}\right]\right\} \\
& =-\operatorname{sgn}\left\{(2-\phi) \phi(1-\phi-\tilde{\phi})^{2}\right\} .
\end{aligned}
$$

As a result, if $\phi>0$ and $1-\phi-\widetilde{\phi}>0$, then $\lambda_{\text {intra }}$ is decreasing in $N$.

With respect to $\lambda_{\text {inter }}$, the term that multiplies $N$ in the denominator (i.e., $(1-\phi)^{2} J-$ $\left.[2(1-\phi)-\widetilde{\phi}] \widetilde{\phi}(J-1)=J(1-\phi-\widetilde{\phi})^{2}+[2(1-\phi)-\widetilde{\phi}] \widetilde{\phi}\right)$ is positive for $\phi<1$. The numerator of $\lambda_{\text {inter }}$ is positive for $\phi>0$, so $\lambda_{\text {inter }}$ decreases with $N$ for $\phi \in(0,1)$.

(iii) We have $\left((1-\phi)^{2}-[2(1-\phi)-\widetilde{\phi}] \widetilde{\phi}\right)=(1-\phi-\widetilde{\phi})^{2} \geq 0$ with equality for $\widetilde{\phi}=$ $1-\phi$. Hence the denominators of both $\lambda_{\text {intra }}$ and $\lambda_{\text {inter }}$ are increasing in $J$ as long as (a) $1-\phi-\widetilde{\phi}>0$ (we have shown already that, if $1-\phi-\widetilde{\phi}=0$, then $\lambda_{\text {intra }}$ and $\lambda_{\text {inter }}$ do not depend on $J$ ) and (b) given this condition, $\lambda_{\text {intra }}$ and $\lambda_{\text {inter }}$ are decreasing in $J$.

(iv) Since $[2(1-\phi)-\widetilde{\phi}] \geq 0$ with equality for $\phi=1$, it is immediate that the minimum value $\lambda_{\text {intra }}$ or $\lambda_{\text {inter }}$ can assume is 0 . We have shown that $\lambda_{\text {intra }}$ and $\lambda_{\text {inter }}$ are either decreasing or constant in $N$. Thus, they attain their maxima when $N=1$, for which

$$
\begin{aligned}
\lambda_{\text {intra }} & =\frac{(2-\phi) \phi+[2(1-\phi)-\widetilde{\phi}] \widetilde{\phi}}{(1-\phi)^{2} J+(2-\phi) \phi-[2(1-\phi)-\widetilde{\phi}] \widetilde{\phi}(J-1)} ; \\
\lambda_{\text {inter }} & =\frac{(2-\phi) \phi}{(1-\phi)^{2} J+(2-\phi) \phi-[2(1-\phi)-\widetilde{\phi}] \widetilde{\phi}(J-1)} .
\end{aligned}
$$


Note that $\lambda_{\text {intra }} \geq \lambda_{\text {inter }}$. Also, $\left((1-\phi)^{2}-[2(1-\phi)-\widetilde{\phi}] \widetilde{\phi}\right) \geq 0$ with equality for $\widetilde{\phi}=$ $1-\phi$. Hence both lambdas attain their maxima for $J=1$, with $\lambda_{\text {intra }}$ 's maximum given by

$$
\begin{aligned}
\lambda_{\text {intra }} & =\frac{(2-\phi) \phi+[2(1-\phi)-\widetilde{\phi}] \widetilde{\phi}}{(1-\phi)^{2}+(2-\phi) \phi}=(2-\phi) \phi+[2(1-\phi)-\widetilde{\phi}] \widetilde{\phi} \\
& =(2-\phi-\widetilde{\phi})(\phi+\widetilde{\phi}) ;
\end{aligned}
$$

this expression is maximized for $\widetilde{\phi}+\phi=1$, which gives a value of 1 .

We conclude that both $\lambda_{\text {intra }}$ and $\lambda_{\text {inter }}$ belong to $[0,1]$.

PROOF OF PROPOSITION 3: The derivative of the relative price of a firm's own sector with respect to employment can be written as follows:

$$
\begin{aligned}
& \frac{\partial \rho_{n}}{\partial L_{n j}} \\
& =-\frac{1}{\theta}\left(\frac{1}{N}\right)^{1 / \theta}\left(\frac{c_{n}}{C}\right)^{-1 / \theta-1} \frac{F^{\prime}\left(L_{n j}\right) C-c_{n} \frac{\theta}{\theta-1} \frac{C}{C^{(\theta-1) / \theta}}\left(\frac{1}{N}\right)^{1 / \theta} \frac{\theta-1}{\theta} c_{n}^{(\theta-1) / \theta-1} F^{\prime}\left(L_{n j}\right)}{C^{2}} \\
& =-\frac{1}{\theta}\left(\frac{1}{N}\right)^{1 / \theta}\left(\frac{c_{n}}{C}\right)^{-1 / \theta}\left[1-\left(\frac{1}{N}\right)^{1 / \theta}\left(\frac{c_{n}}{C}\right)^{(\theta-1) / \theta}\right] \frac{F^{\prime}\left(L_{n j}\right)}{c_{n}} \\
& =-\frac{1}{\theta} \rho_{n}\left[1-\left(\frac{p_{n} c_{n}}{P C}\right)\right] \frac{F^{\prime}\left(L_{n j}\right)}{c_{n}}<0 .
\end{aligned}
$$

The corresponding derivative of the relative price of the other sectors $(m \neq n)$ is

$$
\begin{aligned}
\frac{\partial \rho_{m}}{\partial L_{n j}} & =-\frac{1}{\theta}\left(\frac{1}{N}\right)^{1 / \theta}\left(\frac{c_{m}}{C}\right)^{-1 / \theta-1} \frac{c_{m}}{C} \frac{-1}{C} \frac{\theta}{\theta-1} \frac{C}{C^{(\theta-1) / \theta}}\left(\frac{1}{N}\right)^{1 / \theta} \frac{\theta-1}{\theta} c_{n}^{(\theta-1) / \theta-1} F^{\prime}\left(L_{n j}\right) \\
& =\frac{1}{\theta}\left(\frac{1}{N^{2}}\right)^{1 / \theta}\left(\frac{c_{m}}{C}\right)^{1-1 / \theta}\left(\frac{c_{n}}{C}\right)^{-1 / \theta} \frac{F^{\prime}\left(L_{n j}\right)}{c_{m}} \\
& =\frac{1}{\theta}\left(\frac{p_{m} c_{m}}{P C}\right) \rho_{n} \frac{F^{\prime}\left(L_{n j}\right)}{c_{m}}>0 .
\end{aligned}
$$

Proof of Proposition 4: The expressions in the proof of Proposition 3 imply the following relationship between the change in the relative price of sector $n$ and the changes in the relative prices of the other sectors:

$$
\frac{\partial \rho_{n}}{\partial L_{n j}} c_{n}=-\sum_{m \neq n} \frac{\partial \rho_{m}}{\partial L_{n j}} c_{m} .
$$

Referring to Section 4.2.2, multiplying and dividing by $L$ in the wage effect term, by $c_{n}$ in the own-industry relative price effect term, and by $c_{m}$ in the other industry relative price terms, and using equation (B.3), the first-order condition for firm $n j$ simplifies to

$$
\rho_{n} F^{\prime}\left(L_{n j}\right)-\omega(L)-\omega^{\prime}(L) L\left[s_{n j}^{L}+\lambda_{\text {intra }} s_{n,-j}^{L}+\lambda_{\text {inter }}\left(1-s_{n j}^{L}-s_{n,-j}^{L}\right)\right]
$$




$$
+\frac{\partial \rho_{n}}{\partial L_{n j}} c_{n}\left[s_{n j}+\lambda_{\text {intra }}\left(1-s_{n j}\right)-\lambda_{\text {inter }}\right]=0 ;
$$

here $s_{n j} \equiv F\left(L_{n j}\right) / c_{n}$ is the share of firm $j$ in the total production of sector $n, s_{n j}^{L} \equiv L_{n j} / L$, and $s_{n,-j}^{L} \equiv\left(\sum_{k \neq j} L_{n k}\right) / L$.

For the objective function of firm $j$ in sector $n$, the second derivative is

$$
\begin{aligned}
& \frac{\partial \rho_{n}}{\partial L_{n j}} F^{\prime}\left(L_{n j}\right)+\rho_{n} F^{\prime \prime}\left(L_{n j}\right)-2 \omega^{\prime}(L)-\omega^{\prime \prime}(L)\left[L_{n j}+\lambda_{\text {intra }} \sum_{k \neq j} L_{n k}+\lambda_{\text {inter }} \sum_{m \neq n} \sum_{k=1}^{J} L_{m k}\right] \\
& \quad+\frac{\partial \rho_{n}}{\partial L_{n j}} F^{\prime}\left(L_{n j}\right)\left(1-\lambda_{\text {inter }}\right) \\
& \quad+\frac{\partial^{2} \rho_{n}}{\left(\partial L_{n j}\right)^{2}}\left[F\left(L_{n j}\right)\left(1-\lambda_{\text {inter }}\right)+\left(\lambda_{\text {intra }}-\lambda_{\text {inter }}\right)\left(c_{n}-F\left(L_{n j}\right)\right)\right]
\end{aligned}
$$

Here

$$
\frac{\partial^{2} \rho_{n}}{\left(\partial L_{n j}\right)^{2}}=\frac{\partial \rho_{n}}{\partial L_{n j}}\left[\frac{\partial \rho_{n}}{\partial L_{n j}} \frac{1}{\rho_{n}}\left(1+(\theta-1) \frac{p_{n} c_{n} / P C}{1-p_{n} / c_{n} P C}\right)+\frac{F^{\prime \prime}\left(L_{n j}\right)}{F^{\prime}\left(L_{n j}\right)}-\frac{F^{\prime}\left(L_{n j}\right)}{c_{n}}\right] .
$$

Replacing the latter in our expression (B.4) for the objective function's second derivative and then regrouping terms, we obtain

$$
\begin{aligned}
& \frac{\partial \rho_{n}}{\partial L_{n j}} F^{\prime}\left(L_{n j}\right)\left\{1-\lambda_{\text {inter }}-\left[\left(1-\lambda_{\text {inter }}\right) \frac{F\left(L_{n j}\right)}{c_{n}}+\left(\lambda_{\text {intra }}-\lambda_{\text {inter }}\right) \frac{c_{n}-F\left(L_{n j}\right)}{c_{n}}\right]\right. \\
& \left.\quad \times\left[\frac{1}{\theta}\left(1-\frac{p_{n} c_{n}}{P C}\right)+\left(1-\frac{1}{\theta}\right) \frac{p_{n} c_{n}}{P C}\right]\right\} \\
& \quad+\frac{\partial \rho_{n}}{\partial L_{n j}} F^{\prime}\left(L_{n j}\right)\left\{1-\left[\left(1-\lambda_{\text {inter }}\right) \frac{F\left(L_{n j}\right)}{c_{n}}+\left(\lambda_{\text {intra }}-\lambda_{\text {inter }}\right) \frac{c_{n}-F\left(L_{n j}\right)}{c_{n}}\right]\right\} \\
& \quad+\rho_{n} F^{\prime \prime}\left(L_{n j}\right)+\frac{\partial \rho_{n}}{\partial L_{n j}} c_{n} \frac{F^{\prime \prime}\left(L_{n j}\right)}{F^{\prime}\left(L_{n j}\right)}\left[\left(1-\lambda_{\text {inter }}\right) \frac{F\left(L_{n j}\right)}{c_{n}}+\left(\lambda_{\text {intra }}-\lambda_{\text {inter }}\right) \frac{c_{n}-F\left(L_{n j}\right)}{c_{n}}\right] \\
& \quad-2 \omega^{\prime}(L)-\omega^{\prime \prime}(L)\left[L_{n j}+\lambda_{\text {intra }} \sum_{k \neq j} L_{n k}+\lambda_{\text {inter }} \sum_{m \neq n} \sum_{k=1}^{J} L_{m k}\right] .
\end{aligned}
$$

The first row of this expression is negative because $\frac{\partial \rho_{n}}{\partial L_{n j}}$ is negative, $F^{\prime}$ is positive, and the term in braces is positive since $\left[\frac{1}{\theta}\left(1-\frac{p_{n} c_{n}}{P C}\right)+\left(1-\frac{1}{\theta}\right) \frac{p_{n} c_{n}}{P C}\right]<1$. The term in the second row is clearly negative. The third row's first term is nonpositive but its second term is nonnegative. Yet we can combine them to write

$$
\frac{\partial \rho_{n}}{\partial L_{n j}} c_{n} \frac{F^{\prime \prime}\left(L_{n j}\right)}{F^{\prime}\left(L_{n j}\right)}\left\{-\frac{\theta}{1-p_{n} c_{n} / P C}+\left[\left(1-\lambda_{\text {inter }}\right) \frac{F\left(L_{n j}\right)}{c_{n}}+\left(\lambda_{\text {intra }}-\lambda_{\text {inter }}\right) \frac{c_{n}-F\left(L_{n j}\right)}{c_{n}}\right]\right\},
$$

which is the product of three nonpositive factors (rendering the entire expression nonpositive). The fourth row is strictly negative because, with the constant elasticity functional 
form of utility, it is equal to

$$
-\frac{\omega}{L} \frac{1}{\eta}\left\{2+\left(\frac{1}{\eta}-1\right)\left[s_{n j}^{L}+\lambda_{\text {intra }} s_{n,-j}^{L}+\lambda_{\text {inter }}\left(1-s_{n j}^{L}-s_{n,-j}^{L}\right)\right]\right\} .
$$

The term

$$
\left\{2+\left(\frac{1}{\eta}-1\right)\left[s_{n j}^{L}+\lambda_{\text {intra }} s_{n,-j}^{L}+\lambda_{\text {inter }}\left(1-s_{n j}^{L}-s_{n,-j}^{L}\right)\right]\right\}
$$

is greater than 1 and is also multiplying a negative factor $-\frac{\omega}{L} \frac{1}{\eta}$, so the second-order condition's fourth row is negative.

The objective function of each firm is thus globally strictly concave; therefore, any solution to the system of equations implied by the first-order conditions is an equilibrium. So in order to find the symmetric equilibria, we first simplify the first-order condition of firm $n j$ when it is evaluated at a symmetric equilibrium-using $c_{n}=c$ for all $n$ and $p_{n}=p$ for all $n$-and then note that $c_{n} / C=c / C=1 / N$ in the symmetric case.

In a symmetric equilibrium, the marginal product of labor is equal to $F^{\prime}(L / J N)$. Using this equality and substituting $c_{n} / C=c_{m} / C=1 / N$ in our expression (B.2) for the change in the relative price of the firm's industry when the firm expands employment plans, we can simplify it to

$$
\frac{\partial \rho_{n}}{\partial L_{n j}}=-\frac{1}{\theta}\left(1-\frac{1}{N}\right) \frac{F^{\prime}(L / J N)}{c} .
$$

Dividing the first-order condition by the real wage and then substituting the derivatives of the relative price that we just calculated yields

$$
\begin{aligned}
\frac{F^{\prime}(L / J N)-\omega(L)}{\omega(L)}= & \frac{\omega^{\prime}(L) L}{\omega(L)}\left[s_{n j}^{L}+\lambda_{\text {intra }} s_{n,-j}^{L}+\lambda_{\text {inter }}\left(1-s_{n j}^{L}-s_{n,-j}^{L}\right)\right] \\
& +\frac{1}{\theta}\left(1-\frac{1}{N}\right) \frac{F^{\prime}(L / J N)}{\omega(L)}\left[s_{n j}+\lambda_{\text {intra }}\left(1-s_{n j}\right)-\lambda_{\text {inter }}\right] .
\end{aligned}
$$

In a symmetric equilibrium, the employment share of firm $j$ in sector $n$ is $L_{n j} / L=1 / J N$ for all sectors $n$ and all firms $j$ within that sector-that is, since the employment shares of all firms are the same. Similarly, the product market share of firm $j$ in sector $n$ is $F\left(L_{n j}\right) / c=1 / J$. Plugging these into the previous equation implies that

$$
\begin{aligned}
\mu= & \frac{1}{\eta}\left[\frac{1}{N J}+\frac{\lambda_{\text {intra }}(J-1)}{N J}+\frac{\lambda_{\text {inter }}(N-1)}{N}\right] \\
& +\frac{1+\mu}{\theta}\left(1-\frac{1}{N}\right)\left[\frac{1}{J}+\frac{\lambda_{\text {intra }}(J-1)}{J}-\lambda_{\text {inter }}\right] .
\end{aligned}
$$

We can now express this in terms of MHHI values for the labor market and product markets as follows:

$$
\mu=\frac{1}{\eta} \underbrace{\left[1 / N J+\lambda_{\text {intra }}(J-1) / N J+\lambda_{\text {inter }}(N-1) / N\right]}_{H_{\text {labor }}}
$$




$$
+\frac{1+\mu}{\theta}\{\underbrace{\left[1 / J+\lambda_{\text {intra }}(J-1) / J\right]}_{H_{\text {product }}}-\lambda_{\text {inter }}\}\left(1-\frac{1}{N}\right) .
$$

Here $H_{\text {labor }}$ is the modified HHI for the labor market, which equals $\left(1+\lambda_{\text {intra }}(J-1)+\right.$ $\left.\lambda_{\text {inter }}(N-1) J\right) / N J$, and $H_{\text {product }}$ is the modified HHI for the product market of one industry, which equals $1 / J+\lambda_{\text {intra }}(1-1 / J)$.

The expression for the markup delivers an equation in $L$ :

$$
\omega(L)=\frac{F^{\prime}\left(\frac{L}{J N}\right)}{\frac{1+H_{\text {labor }} / \eta}{1-1 / \theta\left(H_{\text {product }}-\lambda_{\text {inter }}\right)(1-1 / N)}} .
$$

If we combine this equation in $L$ and $w / P$ with the inverse labor supply and then impose labor market clearing, then the result is an equation for the equilibrium level $L$ of employment:

$$
-\frac{U_{L}\left(\frac{w}{P} \frac{L}{N}, \frac{L}{N}\right)}{U_{C}\left(\frac{w}{P} \frac{L}{N}, \frac{L}{N}\right)}=\frac{F^{\prime}\left(\frac{L}{J N}\right)}{\frac{1+H_{\text {labor }} / \eta}{1-1 / \theta\left(H_{\text {product }}-\lambda_{\text {inter }}\right)(1-1 / N)}} .
$$

We can obtain a closed-form solution for the constant-elasticity labor supply and CobbDouglas production function case. In that case, the equilibrium total employment level becomes

$$
\chi^{1 /(1-\sigma)}\left(\frac{L}{N}\right)^{(\xi+\sigma) /(1-\sigma)}=\frac{A \alpha\left(\frac{L}{J N}\right)^{\alpha-1}}{\frac{1+H_{\text {labor }} / \eta}{1-1 / \theta\left(H_{\text {product }}-\lambda_{\text {inter }}\right)(1-1 / N)}} .
$$

This equation has a unique solution for $L$ :

$$
L^{*}=N\left(\frac{\chi^{-1 /(1-\sigma)} A \alpha}{1+\mu^{*}}\right)^{1 /(1 / \eta-(\alpha-1))} J^{-(\alpha-1) /(1 / \eta-(\alpha-1))},
$$

where

$$
1+\mu^{*}=\frac{1+H_{\text {labor }} / \eta}{1-(1 / \theta)\left(H_{\text {product }}-\lambda_{\text {inter }}\right)(1-1 / N)} .
$$

We next prove four claims as follows. The equilibrium markdown of real wages $\mu^{*}$ is:

(1) increasing in $\widetilde{\phi}$;

(2) decreasing in $J$ if $\phi+\widetilde{\phi}<1$ but constant as a function of $J$ if $\phi+\widetilde{\phi}=1$;

(3) decreasing in the elasticity of labor supply $\eta$, and

(4) decreasing in $\theta$, the elasticity of substitution among goods by consumers, if $\phi<1-$ but constant as a function of $\theta$ otherwise. 
(1) According to Lemma 2, both $\lambda_{\text {intra }}$ and $\lambda_{\text {inter }}$ are increasing in $\widetilde{\phi}$ and so likewise is $H_{\text {labor }}$. We also have

$$
\frac{\partial\left(H_{\text {product }}-\lambda_{\text {inter }}\right)}{\partial \widetilde{\phi}}=\frac{J-1}{J} \frac{\partial \lambda_{\text {intra }}}{\partial \widetilde{\phi}}-\frac{\partial \lambda_{\text {inter }}}{\partial \widetilde{\phi}} .
$$

The sign of this expression is given by

$$
\begin{aligned}
\operatorname{sgn} & \left\{\frac{\partial\left(H_{\text {product }}-\lambda_{\text {inter }}\right)}{\partial \widetilde{\phi}}\right\} \\
= & \operatorname{sgn}\left\{\begin{array}{c}
(J-1) / J(1-\phi-\widetilde{\phi}) 2 J N\left[(1-\phi)^{2} N+(2-\phi) \phi\right] \\
-(1-\phi-\widetilde{\phi}) 2 N(J-1)[(2-\phi) \phi+[2(1-\phi)-\widetilde{\phi}] \widetilde{\phi} N]
\end{array}\right\} \\
= & \operatorname{sgn}\left\{(1-\phi-\widetilde{\phi})\left[(1-\phi)^{2} N-[2(1-\phi)-\widetilde{\phi}] \widetilde{\phi} N\right]\right\} \\
= & \operatorname{sgn}\left\{(1-\phi-\widetilde{\phi})^{3}\right\},
\end{aligned}
$$

which is positive for $(1-\phi-\widetilde{\phi})>0$ and so $\left(H_{\text {product }}-\lambda_{\text {inter }}\right)$ is increasing in $\widetilde{\phi}$. Furthermore, $\left(H_{\text {product }}-\lambda_{\text {inter }}\right) \leq 1$ (with equality when $\left.\widetilde{\phi}=1\right)$ and so-in the fraction of our expression for $\mu^{*}>0$ - the numerator is increasing and the denominator is decreasing in $\widetilde{\phi}$; therefore, $\mu^{*}$ increases with $\widetilde{\phi}$.

(2) We have that

$$
\begin{aligned}
H_{\text {product }}-\lambda_{\text {inter }} & =\frac{1+\lambda_{\text {intra }}(J-1)}{J}-\lambda_{\text {inter }} \\
& =\frac{1+\frac{(J-1)[(2-\phi) \phi+[2(1-\phi)-\widetilde{\phi}] \widetilde{\phi} N]}{(1-\phi)^{2} J N+(2-\phi) \phi-[2(1-\phi)-\widetilde{\phi}] \widetilde{\phi} N(J-1)}}{J}-\lambda_{\text {inter }} \\
& =\frac{(1-\phi)^{2} J N+J(2-\phi) \phi}{J\left[(1-\phi)^{2} J N+(2-\phi) \phi-[2(1-\phi)-\widetilde{\phi}]\right] \widetilde{\phi} N(J-1)}-\lambda_{\text {inter }} \\
& =\frac{(1-\phi)^{2} N}{(1-\phi)^{2} J N+(2-\phi) \phi-[2(1-\phi)-\widetilde{\phi}] \widetilde{\phi} N(J-1)},
\end{aligned}
$$

which is decreasing in $J_{\widetilde{\phi}}$ provided that $1-\phi-\widetilde{\phi}>0$ - that is, since $\left((1-\phi)^{2}-[2(1-\right.$ $\phi)-\widetilde{\phi}] \widetilde{\phi})=(1-\phi-\widetilde{\phi})$. If $\phi+\widetilde{\phi}=1$, then $H_{\text {product }}-\lambda_{\text {inter }}$ is constant in $J$.

Consider now

$$
\begin{aligned}
H_{\text {labor }} & =\frac{1+\lambda_{\text {intra }}(J-1)+\lambda_{\text {inter }}(N-1) J}{N J}=\frac{1}{N}\left[\frac{1+\lambda_{\text {intra }}(J-1)}{J}+(N-1) \lambda_{\text {inter }}\right] \\
& =\frac{1}{N}\left[\frac{(1-\phi)^{2} N+(2-\phi) \phi}{(1-\phi)^{2} J N+(2-\phi) \phi-[2(1-\phi)-\widetilde{\phi}] \widetilde{\phi} N(J-1)}+(N-1) \lambda_{\text {inter }}\right] \\
& =\frac{1}{N} \frac{(1-\phi)^{2} N+(2-\phi) \phi+(N-1)(2-\phi) \phi}{(1-\phi)^{2} J N+(2-\phi) \phi-[2(1-\phi)-\widetilde{\phi}] \widetilde{\phi} N(J-1)} \\
& =\frac{1}{(1-\phi)^{2} J N+(2-\phi) \phi-[2(1-\phi)-\widetilde{\phi}] \widetilde{\phi} N(J-1)}
\end{aligned}
$$


which is decreasing in $J$ as long as $1-\phi-\widetilde{\phi}>0$; otherwise, it is constant in $J$. We conclude that: (a) if $1-\phi-\widetilde{\phi}>0$, then the numerator and denominator in the fraction of our expression for $\mu^{*}$ are (respectively) decreasing and increasing in $J$; and (b) if $\phi+\widetilde{\phi}=1$ then those two components are each constant as a function of $J$. So if $1-\phi-\widetilde{\phi}>0$, then the equilibrium markdown decreases with $J$; otherwise, it is unaffected by $J$.

Claims (3) and (4) are straightforward given that $H_{\text {product }}-\lambda_{\text {inter }} \leq 1$ always, $H_{\text {product }}-$ $\lambda_{\text {inter }}>0$ for $\phi<1$, and $H_{\text {labor }}>0$ always.

We now check that $\mu^{*}$ is non-monotone in $\phi$ when $\widetilde{\phi}=0$. We have

$$
\frac{\partial \log \left(1+\mu^{*}\right)}{\partial \phi}=\left\{\frac{\frac{1}{\eta}\left(1-\frac{1}{J N}\right)}{1+\frac{1}{\eta}\left[\frac{1}{J N}+\lambda\left(1-\frac{1}{J N}\right)\right]}-\frac{\frac{1}{\theta J}\left(1-\frac{1}{N}\right)}{1-\frac{1-\lambda}{\theta J}\left(1-\frac{1}{N}\right)}\right\} \frac{\partial \lambda}{\partial \phi} .
$$

This expression is negative whenever $\frac{\theta J}{1-1 / N}-1<\frac{\eta}{1-1 / J N}+\frac{1}{J N-1}$ or $\frac{\theta}{1+\eta}-\frac{N-1}{J N-1}<0$. Q.E.D.

ProOF OF PROPOSITION 6: We have

$$
\frac{\partial^{2} \log L^{*}}{\partial(1-\phi) \partial J}=\frac{1}{\frac{1}{\eta}-(\alpha-1)} \frac{\frac{1}{\eta} \frac{\partial^{2} H}{\partial(1-\phi) \partial J}\left(1+\frac{H}{\eta}\right)-\frac{1}{\eta^{2}} \frac{\partial H}{\partial(1-\phi)} \frac{\partial H}{\partial J}}{\left(1+\frac{H}{\eta}\right)^{2}}>0 .
$$

The reason is that

$$
\operatorname{sgn}\left\{\frac{\partial^{2} H}{\partial(1-\phi) \partial J}\left(1+\frac{H}{\eta}\right)-\frac{1}{\eta} \frac{\partial H}{\partial(1-\phi)} \frac{\partial H}{\partial J}\right\}=\operatorname{sgn}\left\{-\left(1-\frac{1}{J}\right)(1-\lambda) \frac{\partial \lambda}{\partial(1-\phi)}\right\},
$$

which is positive for $J>1$ because $\partial \lambda / \partial(1-\phi)<0$.

Q.E.D.

\section{REFERENCES}

ACEMoglu, D., AND P. Restrepo (2018): “Demographics and Automation,” NBER Working Paper. [1006] (2019): "Automation and New Tasks: How Technology Displaces and Reinstates Labor," Journal of Economic Perspectives, 33, 3-30. [1006]

Acemoglu, D., V. M. Carvalho, A. Ozdaglar, And A. Tahbaz-Salehi (2012): “The Network Origins of Aggregate Fluctuations," Econometrica, 80 (5), 1977-2016. [1004]

Aggarwal, R., S. DahiYa, And N. R. Prabhala (2019): “The Power of Shareholder Votes: Evidence From Uncontested Director Elections," Journal of Financial Economics, 133 (1), 134-153. [1001]

Allen, T., AND C. ARKOlAKIS (2016): “Elements of Advanced International Trade," Online Lecture Notes. Available at www.econ.yale.edu/ ka265/teaching/GradTrade/notes/ClassNotes.pdf. [1016]

Antón, M., F. Ederer, M. Gine, And M. C. Schmalz (2018): “Common Ownership, Competition, and Top Management Incentives," CEPR Discussion Paper. [1005]

Appel, I. R., T. A. Gormley, AND D. B. KeIM (2016): "Passive Investors, not Passive Owners," Journal of Financial Economics, 121, 111-141. [1005]

Arrow, K. (1984): Collected Papers of Kenneth J. Arrow: Social Choice and Justice. Belknap Pr. [1000]

ASKer, J., J. FARre-MENSA, AND A. LJUngQViST (2014): “Corporate Investment and Stock Market Listing: A Puzzle?" The Review of Financial Studies, 28 (2), 342-390. [1026]

AtKeson, A., AND A. Burstein (2008): "Pricing-to-Market, Trade Costs, and International Relative Prices," American Economic Review, 98 (5), 1998-2031. [1000,1002,1004,1023,1027,1032]

Autor, D., D. Dorn, L. F. KATZ, C. PATterson, And J. VAn ReEnen (2020): "The Fall of the Labor Share and the Rise of Superstar Firms," The Quarterly Journal of Economics, 135 (2), 645-709. [1006,1015] 
AZAR, J. (2012): “A New Look at Oligopoly: Implicit Collusion Through Portfolio Diversification,” Ph.D. Thesis, Princeton University. [1000,1001,1032] [1001] (2017): "Portfolio Diversification, Market Power, and the Theory of the Firm," SSRN Working Paper. [1006]

AZAR, J., AND X. VIVES (2018): “Oligopoly, Macroeconomic Performance and Competition Policy,” CEPR Discussion Paper. [1000,1030] (2019a): "Common Ownership and the Secular Stagnation Hypothesis," AEA Papers and Proceedings, 109, 322-326. [1000,1016,1023,1026]

(2019b): “A Kaleckian Job Market Multiplier,” Working Paper. [1001,1028]

(2021): "Supplement to 'General Equilibrium Oligopoly and Ownership Structure'," Econometrica Supplemental Material, 89, https://doi.org/10.3982/ECTA17906. [999]

AZAR, J., I. MARINESCU, AND M. STEINBAUM (2020): “Labor Market Concentration,” Journal of Human Resources. [1006]

Azar, J., M. C. Schmalz, And I. Tecu (2018): "Anti-Competitive Effects of Common Ownership," The Journal of Finance, 73 (4), 1513-1565. [1000,1005,1006]

BACKus, M., C. Conlon, AND M. Sinkinson (2018): "Common Ownership and Competition in the Readyto-Eat Cereal Industry,” Working Paper. [1006]

(2019): “Common Ownership in America: 1980-2017,” NBER Working Paper. [1026]

BAKER, J. (2016): "Overlapping Financial Investor Ownership, Market Power, and Antitrust Enforcement: my Qualified Agreement With Professor Elhauge," Harvard Law Review, 129. [1007]

BANAl-EstaÑol, A., J. SEldESlACHTS, AND X. VIVES (2018): "Financial Markets, Common Ownership, and Product Market Outcomes,” Report. [1027]

BARKAI, S. (2020): "Declining Labor and Capital Shares," The Journal of Finance, 75 (5), 2421-2463. [1006, 1007]

BebchuK, L. A., AND S. HiRst (2019): "Index Funds and the Future of Corporate Governance: Theory, Evidence, and Policy," Columbia Law Review, 119 (8), 2029-2145. [1005]

Benmelech, E., N. Bergman, AND H. Kim (2020): "Strong Employers and Weak Employees: How Does Employer Concentration Affect Wages?" Journal of Human Resources (forthcoming). [1006]

Berger, D., K. HerkenhofF, AND S. Mongey (2019): “Labor Market Power,” NBER Working Paper. [1007]

Bergstrom, T. C., AND H. R. VARIAN (1985): "When Are Nash Equilibria Independent of the Distribution of Agents' Characteristics?” The Review of Economic Studies, 715-718. [1015]

Berle, A. A., AND G. C. Means (1932): “The Modern Corporation and Private Property,”. New York, Macmillan editor. [1005]

BLACKRocK (2019): "BlackRock Investment Stewardship: Protecting Our Clients' Assets for the Long-Term," BlackRock Brochure. [1005]

Blonigen, B. A., AND J. R. PIERCE (2016): "The Effect of Mergers and Acquisitions on Market Power and Efficiency,” NBER Working Paper. [1006]

BOLLER, L., AND F. S. MORTON (2020): “Testing the Theory of Common Stock Ownership,” NBER Working Paper. [1007]

Bolton, P., T. Li, E. Ravina, AND H. L. Rosenthal (2019): “Investor Ideology,” NBER Working Paper. [1005]

Brav, A., W. Jiang, T. LI, And J. Pinnington (2019): "Picking Friends Before Picking (Proxy) Fights: How Mutual Fund Voting Shapes Proxy Contests,” ECGI Working Paper. [1005]

BRESNAHAN, T. F., AND S. C. SAlOP (1986): "Quantifying the Competitive Effects of Production Joint Ventures," International Journal of Industrial Organization, 4 (2), 155-175. [1004]

Brito, D., A. OsóRIO, R. Ribeiro, AND H. VASCONCElOS (2018): "Unilateral Effects Screens for Partial Horizontal Acquisitions: The Generalized HHI and GUPPI," International Journal of Industrial Organization, 59, 127-289. [1001,1005]

BRUN, L., AND I. GONZÁLEZ (2017): “Tobin’s q and Inequality,” SSRN Working Paper. [1007]

CEA (2016)a: "Benefits of Competition and Indicators of Market Power," Discussion paper, White House Council of Economics Advisers. [1007]

CEA (2016)b: "Labor Market Monopsony: Trends, Consequences, and Policy Responses," Discussion paper, White House Council of Economics Advisers. [1007]

Chetty, R., A. Guren, D. Manoli, And A. Weber (2011): "Are Micro and Macro Labor Supply Elasticities Consistent? A Review of Evidence on the Intensive and Extensive Margins," The American Economic Review, 101 (3), 471-475. [1011,1027] 
Cyert, R. M., AND M. H. DeGroot (1973): "An Analysis of Cooperation and Learning in a Duopoly Context," The American Economic Review, 63, 24-37. [1009]

D'ASPREMONT, C., R. D. S. FERREIRA, AND L.-A. GÉRARD-VARET (1990): “On Monopolistic Competition and Involuntary Unemployment,” The Quarterly Journal of Economics, 105 (4), 895-919. [1003]

DE Loecker, J., J. EECKHOUt, AND G. Unger (2020): "The Rise of Market Power and the Macroeconomic Implications," The Quarterly Journal of Economics, 135 (2), 561-644. [1000,1006,1015,1026]

DeAngelo, H. (1981): “Competition and Unanimity,” The American Economic Review, 71 (1), 18-27. [1000]

DENNIS, P. J., K. GERARDI, AND C. SCHENONE (2019): “Common Ownership Does not Have Anti-Competitive Effects in the Airline Industry," FRB Atlanta Working Paper. [1006]

DieTZENBACHER, E., B. SMID, AND B. VOLKERINK (2000): "Horizontal Integration in the Dutch Financial Sector,” International Journal of Industrial Organization, 18, 1223-1242. [1005]

DIXIT, A. (1986): “Comparative Statics for Oligopoly," International Economic Review, 27, 107-122. [1034]

Dixit, A., AND J. E. STIGLITZ (1977): “Monopolistic Competition and Optimum Product Diversity," The American Economic Review, 67 (3), 297-308. [1001,1002,1004,1023-1025,1032]

Edgeworth, F. Y. (1881): Mathematical Psychics: An Essay on the Application of Mathematics to the Moral Sciences. London: Kegan Paul. [1009]

Edmans, A., D. LeVIT, AND D. ReILly (2019): “Governance Under Common Ownership," The Review of Financial Studies, 32, 2673-2719. [1005]

Eggertsson, G., J. RobBins, And E. G. Wold (2018): "Kaldor and Piketty's Facts: The Rise of Monopoly Power in the United States," NBER Working Paper. [1007]

ElHauge, E. R. (2016): “Horizontal Shareholding,” Harvard Law Review, 109 (5). [1000,1007]

FALCH, T. (2010): "The Elasticity of Labor Supply at the Establishment Level," Journal of Labor Economics, 8, 237-266. [1006]

FARRELL, J. (1985): “Owner-Consumers and Efficiency,” Economics Letters, 19 (4), 303-306. [1013]

Fichtner, J., E. M. Heemskerk, AND J. Garcia-Bernardo (2017): "Hidden Power of the Big Three? Passive Index Funds, re-Concentration of Corporate Ownership, and New Financial Risk," Business and Politics, 19 (2), 298-326. [1001]

GABAIX, X. (2011): “The Granular Origins of Aggregate Fluctuations,” Econometrica, 79 (3), 733-772. [999, 1004]

GABSZEWICZ, J. J., AND J.-P. VIAL (1972): "Oligopoly "a la Cournot” in a General Equilibrium Analysis," Journal of Economic Theory, 4 (3), 381-400. [1000,1003]

GENG, H., H. HAU, AND S. LAI (2016): “Technological Progress and Ownership Structure,” CEPR Discussion Paper. [1005]

GinsburGH, V. (1994): “In the Cournot-Walras General Equilibrium Model, There May Be ‘More to Gain’ by Changing the Numeraire Than by Eliminating Imperfections: A Two-Good Economy Example," Discussion paper, ULB-Universite Libre de Bruxelles. [1000]

GoRDON, R. H. (1990): “Do Publicly Traded Corporations Act in the Public Interest?” NBER Working Paper. [1000]

GRAMLICH, J., AND S. GRUNDL (2017): “Estimating the Competitive Effects of Common-Ownership,” FEDS Working Paper. [1006]

GrUllon, G., Y. LARKIN, AND R. Michaely (2019): "Are US Industries Becoming More Concentrated?" Review of Finance, 23, 697-743. [1006]

GUTIÉRREZ, G., AND T. PHILIPPON (2017a): “Declining Competition and Investment in the US,” NBER Working Paper. [1007]

_ (2017b): "Investment-Less Growth: An Empirical Investigation," Brookings Papers on Economic Activity, 89-190. [1006]

HALL, R. E. (2018): "New Evidence on the Markup of Prices Over Marginal Costs and the Role of Mega-Firms in the US Economy," NBER Working Paper. [1026]

HANSEN, R. G., AND J. R. LOTT (1996): "Externalities and Corporate Objectives in a World With Diversified Shareholder/Consumers," Journal of Financial and Quantitative Analysis, 31 (1), 43-68. [1000,1006]

HART, O. D. (1979): "On Shareholder Unanimity in Large Stock Market Economies," Econometrica, 47, 10571083. [1000]

(1982): "A Model of Imperfect Competition With Keynesian Features," The Quarterly Journal of Economics, 97, 109-138. [1003]

(1983): "Imperfect competition in general equilibrium: An overview of recent work," (Now published in Frontiers of economics, ed. by K. Arrow and S. Honkapohja. (Basil Blackwell, Oxford, 1985)). [1000]

HE, J., AND J. HuANG (2017): "Product Market Competition in a World of Cross Ownership: Evidence From Institutional Blockholdings," Review of Financial Studies, 30, 2674-2718. [1004,1005] 
HE, J., J. HuANG, AND S. ZHAO (2019): "Internalizing Governance Externalities: The Role of Institutional Cross-Ownership," Journal of Financial Economics, 134, 400-418. [1005]

HeAth, D., D. MACCIOCChI, R. Michaely, AND M. RingGenberg (2019): "Do Index Funds Monitor?" Swiss Finance Institute Research Paper (19-08). [1005]

HOBIJN, B., AND F. NECHIO (2015): "Sticker Shocks: Using VAT Changes to Estimate Upper-Level Elasticities of Substitution," Journal of the European Economic Association. [1027]

JAHNKE, P. (2019): "Ownership Concentration and Institutional Investors' Governance Through Voice and Exit," Business and Politics, 1-24. [1005]

KALECKI, M. (1938): “The Determinants of Distribution of the National Income," Econometrica, 6, 97-112. $[1003,1004]$

(1954): Theory of Economic Dynamics an Easy on Cyclical and Long-Run Changes in Capitalist Economy. Unwin Brothers Limited. [1003,1004]

KARABARbOUnIS, L., AND B. NeIMAN (2019): “Accounting for Factorless Income," NBER Macroeconomics Annual, 33 (1), 167-228. [1007]

KeHRIG, M., AND N. VINCENT (2018): “The Micro-Level Anatomy of the Labor Share Decline,” NBER Working Paper. [1006,1015]

Kennedy, P., D. P. O'Brien, M. Song, AND K. WAEHReR (2017): “The Competitive Effects of Common Ownership: Economic Foundations and Empirical Evidence,” SSRN Working Paper. [1006]

LEWELLEN, J., AND K. LEWELLEN (2018): "Institutional Investors and Corporate Governance: The Incentive to Be Engaged," SSRN Working Paper. [1005]

LÓPEZ, Á. L., AND X. VIVES (2019): “Overlapping Ownership, R\&D Spillovers, and Antitrust Policy,” Journal of Political Economy, 127 (5), 2394-2437. [1004,1015,1016]

MAGILl, M., M. QUINZII, AND J.-C. RocheT (2015): "A Theory of the Stakeholder Corporation," Econometrica, 83 (5), 1685-1725. [1004]

MAS-COLELL, A. (1982): "The Cournotian Foundations of Walrasian Equilibrium Theory: An Exposition of Recent Theory," in Advances in Economic Theory: Invited Papers for the Fourth World Congress of the Econometric Society, 183-224. [1000,1003]

Mas-COlEll, A., AND J. Silvestre (1991): "A Note on Cost-Share Equilibrium and Owner-Consumers," Journal of Economic Theory, 54 (1), 204-214. [1013]

MATSUDAIRA, J. D. (2013): "Monopsony in the Low-Wage Labor Market? Evidence From Minimum Nurse Staffing Regulations," The Review of Economics and Statistics, 96, 92-102. [1006]

NAIN, A., AND Y. WANG (2018): "The Product Market Impact of Minority Stake Acquisitions," Management Science, 64, 825-844. [1005]

NEARY, J. P. (2003a): “Globalization and Market Structure," Journal of the European Economic Association, 1 (2-3), 245-271. [1000,1002,1004,1032]

- (2003b): "The Road Less Travelled: Oligopoly and Competition Policy in General Equilibrium," in Economics for an Imperfect World: Essays in Honor of Joseph Stiglitz. [1000,1002,1023-1025,1031,1032]

NEKARDA, C. J., AND V. A. RAMEY (2019): “The Cyclicality of the Price-Cost Markup,” Working Paper. [1026]

NovsheK, W., AND H. SONNENSCHEIN (1978): "Cournot and Walras Equilibrium," Journal of Economic Theory, 19, 223-266. [1003]

O’Brien, D. P., AND S. C. SAlop (2000): “Competitive Effects of Partial Ownership: Financial Interest and Corporate Control," Antitrust Law Journal, 67 (2), 559-614. [1004,1008]

O'BRIEN, D. P., AND K. WAEHRER (2017): "The Competitive Effects of Common Ownership: We Know Less Than We Think," Antitrust Law Journal, 81 (3), 729-776. [1006]

Posner, E. A., F. M. Scott Morton, AND E. G. Weyl (2017): "A Proposal to Limit the Anti-Competitive Power of Institutional Investors," Antitrust Law Journal, 81 (3), 669-728. [1000,1007]

RANSOM, M. R., AND D. P. SIMS (2010): "Estimating the Firms's Labor Supply Curve in a New Monopsony Framework: School Teachers in Missouri," Journal of Labor Economics, 28, 331-355. [1006]

REYNOLDS, R. J., AND B. R. SNAPP (1986): “The Competitive Effects of Partial Equity Interests and Joint Ventures," International Journal of Industrial Organization, 4, 141-153. [1004]

RINZ, K. (2018): “Labor Market Concentration, Earnings Inequality, and Earnings Mobility,” Discussion paper, Center for Economic Studies, US Census Bureau. [1007]

ROCK, E. B., AND D. L. RUBinfeld (2017): "Defusing the Antitrust Threat to Institutional Investor Involvement in Corporate Governance," NYU Law and Economics Research Paper. [1007]

Rossi-HANSBERG, E., P.-D. SARTE, AND N. TRACHTER (2018): "Diverging Trends in National and Local Concentration," NBER Working Paper. [1007]

RotemberG, J. (1984): “Financial Transaction Costs and Industrial Performance,” MIT Sloan Working Paper. [1000,1004] 
RUBinSTEIN, A., AND M. E. YAARI (1983): “The Competitive Stock Market as Cartel Maker: Some Examples,” STICERD-Theoretical Economics Paper Series, 84. [1004]

SCHMIDT, C., AND R. FAHLENBRACH (2017): "Do Exogenous Changes in Passive Institutional Ownership Affect Corporate Governance and Firm Value?" Journal of Financial Economics, 124 (2), 285-306. [1005]

Scott MorTon, F. M., AND H. J. HovenKamp (2018): "Horizontal Shareholding and Antitrust Policy," The Yale Law Journal, 2017, 2026-2047. [1007]

SHAPIRO, C. (2018): "Antitrust in a Time of Populism," International Journal of Industrial Organization, 61, 714-748. [1007]

SiLVESTRE, J. (1993): “The Market-Power Foundations of Macroeconomic Policy,” Journal of Economic Literature, 31 (1), 105-141. [1003]

Staiger, D. O., J. SpetZ, AND C. S. Phibbs (2010): "Is There Monopsony in the Labor Market? Evidence From a Natural Experiment," Journal of Labor Economics, 28 (2), 211-236. [1006]

STiglitZ, J. (2017): "Inequality, Stagnation, and Market Power," Roosevelt Institute Working Paper. [1006]

Summers, L. (2016): "Corporate Profits Are Near Record Highs. Here's Why That's a Problem," Washington Post. Available at https:/www.washingtonpost.com/news/wonk/wp/2016/03/30/ larry-summers-corporate-profits-are-near-record-highs-heres-why-thats-a-problem/. [1006]

TRAINA, J. (2018): "Is Aggregate Market Power Increasing? Production Trends Using Financial Statements," Stigler Center Working Paper Series No. 17. [1007]

VIVES, X. (1999): Oligopoly Pricing: Old Ideas and New Tools. MIT Press. [1012,1028,1030,1034]

(2020): "Common Ownership, Market Power, and Innovation," International Journal of Industrial Organization, 70, 102528. [1005]

Co-editor Charles I. Jones handled this manuscript as an invited Walras-Bowley lecture. The invitation to deliver the Walras-Bowley lecture is also an invitation to publish a suitable version of the lecture in Econometrica.

Manuscript received 9 December, 2019; final version accepted 4 September, 2020; available online 29 September, 2020. 